\title{
North Atlantic Oscillation response in GeoMIP experiments G6solar and G6sulfur: why detailed modelling is needed for understanding regional implications of solar radiation management
}

\author{
Andy Jones ${ }^{1}$, Jim M. Haywood ${ }^{1,2}$, Anthony C. Jones ${ }^{3}$, Simone Tilmes ${ }^{4}$, Ben Kravitz ${ }^{5,6}$, and Alan Robock \\ ${ }^{1}$ Met Office Hadley Centre, Exeter, EX1 3PB, UK \\ ${ }^{2}$ Global Systems Institute, College of Engineering, Mathematics and Physical Sciences, University of Exeter, \\ Exeter, EX4 4QE, UK \\ ${ }^{3}$ Met Office, Exeter, EX1 3PB, UK \\ ${ }^{4}$ Atmospheric Chemistry, Observations and Modeling Laboratory, National Center for Atmospheric Research, \\ Boulder, CO 80307, USA \\ ${ }^{5}$ Department of Earth and Atmospheric Sciences, Indiana University, Bloomington, IN 47405-1405, USA \\ ${ }^{6}$ Atmospheric Sciences and Global Change Division, Pacific Northwest National Laboratory, Richland, WA 99352, USA \\ ${ }^{7}$ Department of Environmental Sciences, Rutgers University, New Brunswick, NJ 08901-8551, USA
}

Correspondence: Andy Jones (andy.jones@metoffice.gov.uk)

Received: 31 July 2020 - Discussion started: 17 August 2020

Revised: 3 December 2020 - Accepted: 13 December 2020 - Published: 29 January 2021

\begin{abstract}
The realization of the difficulty of limiting globalmean temperatures to within 1.5 or $2.0^{\circ} \mathrm{C}$ above preindustrial levels stipulated by the 21 st Conference of Parties in Paris has led to increased interest in solar radiation management (SRM) techniques. Proposed SRM schemes aim to increase planetary albedo to reflect more sunlight back to space and induce a cooling that acts to partially offset global warming. Under the auspices of the Geoengineering Model Intercomparison Project, we have performed model experiments whereby global temperature under the highforcing SSP5-8.5 scenario is reduced to follow that of the medium-forcing SSP2-4.5 scenario. Two different mechanisms to achieve this are employed: the first via a reduction in the solar constant (experiment G6solar) and the second via modelling injections of sulfur dioxide (experiment G6sulfur) which forms sulfate aerosol in the stratosphere. Results from two state-of-the-art coupled Earth system models (UKESM1 and CESM2-WACCM6) both show an impact on the North Atlantic Oscillation (NAO) in G6sulfur but not in G6solar. Both models show a persistent positive anomaly in the NAO during the Northern Hemisphere winter season in G6sulfur, suggesting an increase in zonal flow and an increase in North Atlantic storm track activity impacting the Eurasian conti-
\end{abstract}

nent and leading to high-latitude warming over Europe and Asia. These results are broadly consistent with previous findings which show similar impacts from stratospheric volcanic aerosol on the NAO and emphasize that detailed modelling of geoengineering processes is required if accurate impacts of SRM effects are to be simulated. Differences remain between the two models in predicting regional changes over the continental USA and Africa, suggesting that more models need to perform such simulations before attempting to draw any conclusions regarding potential continental-scale climate change under SRM.

\section{Introduction}

Successive Intergovernmental Panel on Climate Change (IPCC) reports (e.g. Forster et al., 2007; Myhre et al., 2013) have highlighted that anthropogenic greenhouse gas emissions exert a strong positive radiative forcing, leading to a warming of Earth's climate. However, the same IPCC reports also suggest that aerosols of anthropogenic origin exert a significant (but poorly quantified) negative radiative forcing, leading to a cooling effect on the Earth's climate through 
aerosol-radiation and aerosol-cloud interactions. Aerosols have therefore been at the forefront of discussions about increasing planetary albedo by deliberate injection either into the stratosphere (stratospheric aerosol intervention, SAI; Dickinson, 1996) or into marine boundary layer clouds (marine cloud brightening, MCB; e.g. Latham, 1990). Such putative albedo-increasing interventions are referred to as solar radiation management (SRM) geoengineering.

Initial simulations of the impacts of SAI and MCB were carried out by individual groups using models of varying complexity for a range of different scenarios, but the range of different scenarios applied to the models meant that definitive reasons for differences in model responses were difficult to establish (e.g. Rasch et al., 2008; Jones et al., 2010). The Geoengineering Model Intercomparison Project (GeoMIP) framework was therefore established with specific protocols for performing model simulations under a range of defined scenarios (Kravitz et al., 2011). The scenarios considered by GeoMIP have themselves evolved with the earliest idealized simulations being supplemented by progressively more complex scenarios aiming to address more specific policy-relevant questions. The earliest simulations involved balancing an abrupt quadrupling of atmospheric carbon dioxide concentrations by simply reducing the solar constant (GeoMIP experiment G1; Kravitz et al., 2011). While such simulations are highly idealized, the simplicity of the scenario means that many climate models could perform the simulations, providing a robust multi-model assessment (Kravitz et al., 2013, 2020).

Policy-relevant questions regarding SRM can only be addressed by climate model simulations that represent deployment strategies which use technologies that are considered safe, cost-effective and have a reasonably short development time (Royal Society, 2009). SAI has been suggested as one such potentially plausible mechanism; its plausibility is enhanced by observations of explosive or effusive volcanic eruptions which cause a periodic negative radiative forcing and a cooling of the Earth's climate (e.g. Robock, 2000; Haywood et al., 2013; Santer et al., 2014; Malavelle et al., 2017). Observations of such natural analogues provide powerful constraints on the ability of global climate models to represent complex aerosol-radiation and aerosol-cloud processes, although the pulse-like nature of the emissions from volcanic eruptions means that they are not perfect analogues for SRM (Robock et al., 2013). Single model simulations which include treatments of aerosol processes associated with SAI (e.g. Jones et al., 2017, 2018; Irvine et al., 2019) have shown that policy-relevant climate metrics at global, continental and regional scales such as sea-level rise, sea-ice extent, European heat waves, Atlantic hurricane frequency and intensity, and North Atlantic storm track displacement can be significantly ameliorated under SAI geoengineering compared with baseline (non-geoengineered) scenarios. Additionally, SAI strategies could potentially be tailored to provide spatial distributions of stratospheric aerosol that mitigate some of the residual impacts of SAI such as the overcooling of the tropics and undercooling of polar latitudes that are evident under more generic SAI strategies (e.g. MacMartin et al., 2013; Tilmes et al., 2018). However, studies suggest that SAI would by no means ameliorate all effects of climate change (e.g. Simpson et al., 2019; Da-Allada et al., 2020; Robock, 2020).

The North Atlantic Oscillation (NAO) can be defined as a change in the pressure difference between the Icelandic Low and the Azores High pressure regions (e.g. Hurrell, 1995), and by convention, a positive NAO anomaly is associated with an increase in the surface pressure gradient between these regions. Both model simulations (e.g. Stenchikov et al., 2002) and observations (e.g. Graf et al., 1994; Kodera, 1994; Lorenz and Hartmann, 2003) have shown that one of the most significant atmospheric responses following explosive volcanic eruptions is a strengthening of the polar vortex and an impact on the Northern Hemisphere wintertime NAO, although in the case of the 1991 Pinatubo eruption the causal link has recently been questioned by Polvani et al. (2019). Shindell et al. (2004) provide a concise summary of the mechanism by which volcanic stratospheric aerosols are thought to influence the dynamical response of the NAO, leading to wintertime warming over Eurasia and North America (Robock and Mao, 1992). Essentially, (1) sunlight absorbed by aerosols leads to heating of the lower stratosphere, which enhances the meridional temperature gradient; (2) this leads to a strengthening of the westerly zonal winds near the tropopause; (3) planetary waves propagating upwards in the troposphere are refracted away from the pole due to the change in wind shear, further strengthening the westerlies; (4) the enhanced westerlies propagate down to the surface via a positive feedback between the zonal wind anomalies and tropospheric eddies; and (5) strengthened westerly flow near the ground creates the surface pressure and temperature response patterns. As SAI geoengineering could be considered equivalent to a continuous volcanic eruption, it seems plausible that it too could generate similar anomalies in the NAO and so surface temperature.

In addition to work on the dynamical features and NAO response to SAI via volcanic eruptions, there has been much debate on the influence of the 11-year solar cycle with stronger solar activity being associated with a positive phase of the NAO and weaker solar activity being associated with a negative phase. Early work (e.g. Kodera, 2002; Kodera and Kuroda, 2005; Matthes et al., 2006) suggested that mechanisms influencing the NAO from solar variability originated near the stratopause, propagated downward through the stratosphere and influenced the troposphere via changes in meridional propagation of planetary waves. More recent work has suggested that stronger correlations exist between the solar cycle and the phase and strength of the NAO if a lag is accounted for (Gray et al., 2013), owing to oceanatmosphere interactions that strengthen the response (Scaife et al., 2013). These lagged responses to solar cycles have been replicated in some climate models (e.g. Ineson et al., 
2011), including a version of the model that was the forerunner of the UKESM1 model that is used in our analysis (see Sect. 2).

Stratospheric aerosol and the 11-year solar cycle are not the only phenomena to influence the NAO: Smith et al. (2016) indicate that Atlantic sea-surface temperatures, the phase and strength of El Niño, the quasi-biennial oscillation, Atlantic multi-decadal variability, and Pacific decadal variability may all play a role. However, skilful predictions of the wintertime NAO index using sophisticated seasonal prediction models that account for these factors are now possible (Dunstone et al., 2016). Note that the two driving mechanisms investigated in this study, i.e. SAI and a reduction in solar constant, may induce opposing impacts on the NAO: SAI might strengthen the NAO, while reducing the solar constant might weaken it.

The most recent GeoMIP Phase 6 scenarios (GeoMIP6; Kravitz et al., 2015) attempt to provide more policy-relevant information on SRM geoengineering by aligning with the Coupled Model Intercomparison Project Phase 6 (CMIP6; Eyring et al., 2016). Two GeoMIP6 experiments will be considered here: G6solar and G6sulfur. In both experiments the modelled global-mean temperature under a high-forcing scenario is reduced to that in a medium-forcing scenario. The mechanism for performing the temperature reduction is either an idealized reduction of the solar constant (experiment G6solar) or a more realistic injection of sulfur dioxide into the stratosphere (experiment G6sulfur) where it forms sulfate aerosol that reflects sunlight back to space. We examine results from two Earth system models which have performed both experiments (UKESM1 and CESM2WACCM6). The main objective is to determine whether, under SRM strategies which are continuous rather than sporadic or periodic in nature, the two models produce NAO responses that are consistent with the expectations discussed above, i.e. that SAI induces a significant shift to the positive phase of the NAO compared with reducing the solar constant. Our analysis focuses on the broad-scale microphysical, chemical and dynamical features in the Northern Hemisphere winter, i.e. aerosol spatial distributions, impacts on ozone, stratospheric temperatures, stratospheric and tropospheric zonal mean winds, and induced surface pressure patterns with a focus on the NAO, before examining impacts on continental-scale temperature and precipitation patterns. SAI is considered the most plausible SRM method, owing to considerations of effectiveness, timeliness, cost and safety (e.g. Royal Society, 2009). Our focus is therefore on the difference between the responses to SRM via SAI and that via generic reductions in the solar constant, noting that many previous assessments of the impacts of SRM use a reduction of the solar constant as a proxy for SAI.

Section 2 provides a brief description of the UKESM1 and CESM2-WACCM6 models. Section 3 provides a description of the experimental design of the G6solar and G6sulfur ex- periments. Results are presented in Sect. 4 before discussions and conclusions are presented in Sect. 5.

\section{Model description}

Both UKESM1 and CESM2-WACCM6 are fully coupled Earth system models which have contributed to CMIP6 and GeoMIP6. Both models (or their immediate forebears) have undergone various degrees of validation relevant to SAI using observations from explosive volcanic eruptions (e.g. Haywood et al., 2010; Dhomse et al., 2014; Mills et al., 2016).

UKESM1 is described by Sellar et al. (2019). It comprises an atmosphere model based on the Met Office Unified Model (UM; Walters et al., 2019; Mulcahy et al., 2018) with a resolution of $1.25^{\circ}$ latitude by $1.875^{\circ}$ longitude with 85 levels up to approximately $85 \mathrm{~km}$, coupled to a $1^{\circ}$ resolution ocean model with 75 levels (Storkey et al., 2018). It includes components to model tropospheric and stratospheric chemistry (Archibald et al., 2020) and aerosols (Mann et al., 2010), sea ice (Ridley et al., 2018), the land surface and vegetation (Best et al., 2011), and ocean biogeochemistry (Yool et al., 2013).

CESM2-WACCM6 is described by Danabasoglu et al. (2020) and Gettelman et al. (2019a). The atmosphere model has a resolution of $0.95^{\circ}$ in latitude by $1.25^{\circ}$ in longitude with 70 levels from the surface to about $140 \mathrm{~km}$. This is coupled to an ocean model component with a nominal $1^{\circ}$ resolution and 60 vertical levels (Danabasoglu et al., 2012) and a sea-ice model (Hunke et al., 2015). It includes a full stratospheric chemistry scheme that is coupled to the atmospheric dynamics, aerosol and radiation schemes (Mills et al., 2017), and a land model with interactive carbon and nitrogen cycles (Danabasoglu et al., 2020).

\section{G6solar and G6sulfur experimental design}

As described in Kravitz et al. (2015), the goal of GeoMIP experiments G6solar and G6sulfur is to modify simulations based on ScenarioMIP high-forcing scenario SSP5-8.5 (O'Neill et al., 2016; experiment ssp585) so as to follow the evolution of the medium-forcing scenario SSP2-4.5 (experiment ssp245). Kravitz et al. (2015) define the criterion for comparing the modified simulations with their ssp245 target in terms of radiative forcing. This was subsequently found to be impractical for some models, so for GeoMIP6 the criterion applied was that for each decade from 2021 to 2100 the global decadal-mean near-surface air temperature of G6solar or G6sulfur should be within $0.2 \mathrm{~K}$ of the corresponding decade of each model's ssp245 simulation. Experiment G6solar performs the required modification in an idealized manner by gradually reducing the solar constant over the 21st century, whereas G6sulfur achieves it by the arguably more technologically feasible method of injecting gradually increasing amounts of $\mathrm{SO}_{2}$ into the lower stratosphere. $\mathrm{SO}_{2}$ 
was injected continuously between $10^{\circ} \mathrm{N}-10^{\circ} \mathrm{S}$ along the Greenwich meridian at $18-20 \mathrm{~km}$ altitude in UKESM1 and on the Equator at the date line at $\sim 25 \mathrm{~km}$ altitude in CESM2WACCM6.

The results presented are ensemble means of three (UKESM1) or two (CESM2-WACCM6) members. These are ultimately initial condition ensembles: the G6solar and G6sulfur ensemble members are based on ensemble members of each model's ssp585 experiment, which are themselves continuations of corresponding CMIP6 historical simulations, which in turn are initialized from different points in each model's pre-industrial control simulation.

We investigate the impact of SAI by examining differences between G6sulfur and G6solar, generally over the final 20 years of the 21 st century. We are thereby comparing two experiments in which the temperature evolution is nominally the same, but they achieve this by different methods. This should highlight any impacts which are captured by a more detailed treatment of modelling SAI geoengineering (G6sulfur) which are not seen when geoengineering is treated in a more idealized fashion (G6solar).

\section{Results}

We first provide a brief analysis of the levels of success that G6sulfur and G6solar have in reducing the temperature change to that of ssp245. As the experimental design assures that the decadal-mean temperature in G6sulfur and G6solar are within $0.2 \mathrm{~K}$ of the values for ssp 245 , we do not show the temporal evolution of temperature, but there is some merit in examining the inter-model and inter-forcing differences of the resulting spatial patterns of temperature change to give context to the results that follow. When analysing the results from the simulations, we generally focus on the difference "G6sulfur minus G6solar" for several key variables that are associated with our understanding of the influence of stratospheric aerosol on the development of NAO anomalies.

\subsection{Spatial distribution of 21st century temperature change}

The spatial pattern of the global-mean temperature change is calculated as the change from present day (PD; mean of 2011-2030) compared with the period 2081-2100 and is shown for experiments ssp245, G6solar and G6sulfur for UKESM1 and CESM2-WACCM6 in Fig. 1. PD data are from years 2011-2014 of each model's CMIP6 historical experiment combined with years 2015-2030 from the corresponding ssp245 experiment.

It is obvious from Fig. 1 that the inter-model differences in temperature response (i.e. the differences between the top and bottom rows) are much greater than the inter-forcing differences in temperature response (i.e. the differences between the columns in any one row). In UKESM1 the warm- ing is around $2.6 \mathrm{~K}$ compared with present day, while for CESM2-WACCM6 the warming is more moderate at around $1.9 \mathrm{~K}$. This result is interesting in itself because the base models that are used in these simulations have been diagnosed as having equilibrium climate sensitivities (i.e. for a doubling of $\mathrm{CO}_{2}$ ) of $5.4 \mathrm{~K}$ (UKESM1; Andrews et al., 2019) and 5.3 K (CESM2; Gettelman et al., 2019b); one might thus expect a similar transient climate response under the SSP24.5 scenario.

Both models warm over land regions more than over ocean regions as documented in successive IPCC reports (e.g. Forster et al., 2007; Myhre et al., 2013). UKESM1 shows a strong polar amplification, particularly in the Northern Hemisphere, while polar amplification is more muted in CESM2-WACCM6. This is likely linked to differences in poleward atmospheric and oceanic heat transport. Indeed, CESM2-WACCM6 suggests that areas of the North Atlantic are subject to a cooling as the mean climate warms. This is presumably as a result of a strong reduction of the Atlantic Meridional Overturning Circulation, which has been documented to collapse in CESM2 from a present-day level of $\sim 23$ to $\sim 8 \mathrm{~Sv}$ (sverdrup) by 2100 under the SSP58.5 scenario (Muntjewerf et al., 2020; Tilmes et al., 2020). UKESM1 shows no such behaviour.

The similarity between the inter-forcing patterns of temperature responses in ssp245, G6solar and G6sulfur for each model is quite striking. On the basis of such an analysis, it would be tempting to conclude that G6solar, which has the benefits of being relatively simple to implement in a great number of climate models (e.g. Kravitz et al., 2013, 2020), might be a reasonable analogue for the far more complex G6sulfur simulations. This conclusion will be examined in the following sections.

\section{2 $\mathrm{SO}_{2}$ injection rate and aerosol optical depth}

In G6sulfur the mean $\mathrm{SO}_{2}$ injection rate during the final 2 decades (2081-2100) is $19.0 \mathrm{Tg} \mathrm{yr}^{-1}$ for UKESM1 and $20.6 \mathrm{Tg} \mathrm{yr}^{-1}$ for CESM2-WACCM6. Such injection rates are broadly similar to the amount injected by the 1991 eruption of Mt Pinatubo (Guo et al., 2004), but unlike the latter they continue year on year. Such large, persistent perturbations are obviously different to the pulse-like injection and subsequent exponential decay of explosive volcanic eruptions (e.g. Jones et al., 2016a), which suggests that one cannot simply assume that the responses to such SAI would be analogous to those from volcanic eruptions. The injection rates by the end of the century have to be so large to counteract the warming due to the increased concentration of atmospheric carbon dioxide which has accumulated over the period 1850-2100. While such injection rates appear high, they are typical in model geoengineering studies. A previous GeoMIP experiment known as G3 (Kravitz et al., 2011) involved injecting increasing amounts of $\mathrm{SO}_{2}$ to offset anthropogenic radiative forcing in the RCP4.5 scenario (Thomson et al., 2011) over 


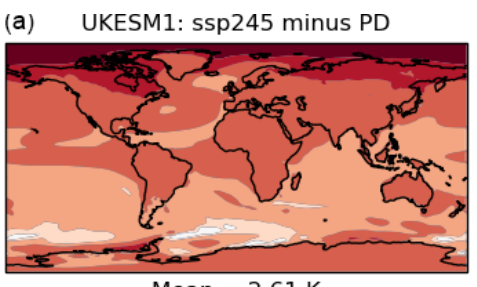

Mean $=2.61 \mathrm{~K}$

(d) CESM2-WACCM6: ssp245 minus PD

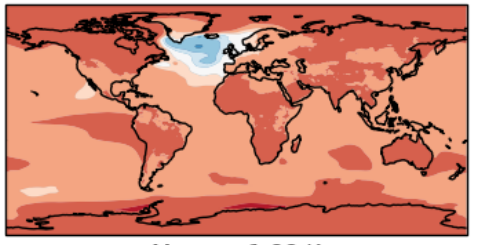

Mean $=1.88 \mathrm{~K}$

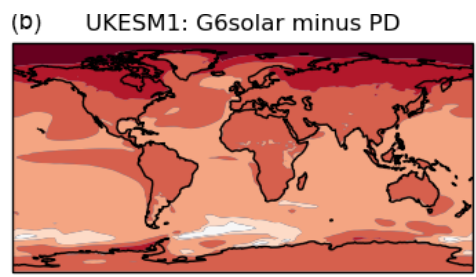

Mean $=2.58 \mathrm{~K}$

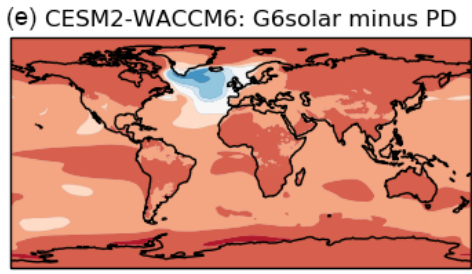

Mean $=1.91 \mathrm{~K}$

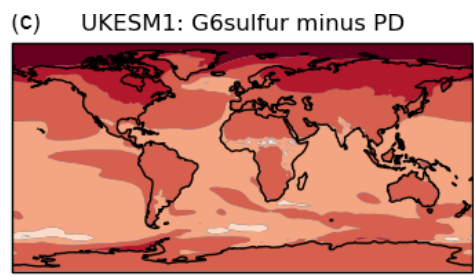

Mean $=2.68 \mathrm{~K}$

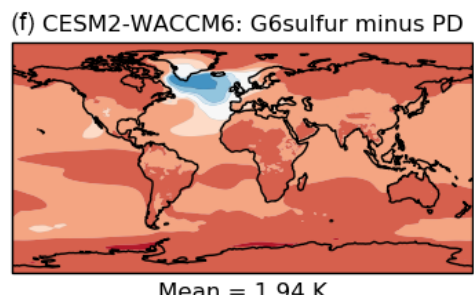

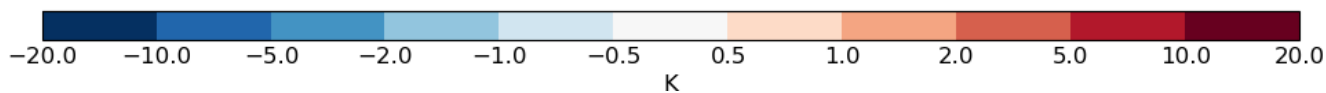

Figure 1. Annual-mean temperature change (K) from present day (PD; 2011-2030 mean) to the end of the century (2081-2100 mean) in the various experiments. Upper row (a, b, c) shows results from UKESM1 and lower row (d, e, f) for CESM2-WACCM6. All results are ensemble means (three members for UKESM1, two for CESM2-WACCM6).

the period 2020-2070, and Niemeier et al. (2013) found that an injection rate of around $12 \mathrm{Tg}$ of $\mathrm{SO}_{2} \mathrm{yr}^{-1}$ was needed in their model by 2070 . Niemeier and Timmreck (2015) suggested a massive $90 \mathrm{Tg}$ of $\mathrm{SO}_{2} \mathrm{yr}^{-1}$ would be needed by 2100 to offset the temperature change in the RCP8.5 scenario (Riahi et al., 2011) in a model that explicitly simulated the evolution of aerosol microphysics to larger sizes via condensation and coagulation as the injection rate increased. The increase in aerosol size leads to a decreased cooling efficiency per unit mass with increasing $\mathrm{SO}_{2}$, owing to decreased stratospheric lifetime (caused by higher aerosol terminal velocities) and also less efficient cooling in the shortwave part of the spectrum along with a stronger counterbalancing impact on terrestrial radiation (Niemeier and Timmreck, 2015). Both UKESM1 and CESM2-WACCM6 include these microphysical mechanisms, so the injection rates used here are by no means exceptional in SAI geoengineering studies.

The resulting anomalies in annual-mean aerosol optical depth (AOD, determined at $550 \mathrm{~nm}$ ) for 2081-2100 are 0.33 for UKESM1 and 0.28 for CESM2-WACCM6; their geographic distributions are shown in Fig. 2.

By 2081-2100 the AOD needed to reduce the SSP58.5 temperature levels to those of SSP2-4.5 is some $18 \%$ greater for UKESM1 than for CESM2-WACCM6, although the amount of cooling produced in the two models is very similar $(-2.47 \mathrm{~K}$ for UKESM1 and $-2.33 \mathrm{~K}$ for CESM2WACCM6). This can be attributed to the different $\mathrm{SO}_{2}$ injection strategies and to different transport strengths from the tropics to the poles in the Brewer-Dobson circulation of the stratosphere. In UKESM1 there is considerably more geoengineered AOD in the tropical reservoir (e.g. Grant et al., 1996) than in CESM2-WACCM6 where the transport to higher latitudes is more efficient.

\subsection{Stratospheric ozone}

Stratospheric aerosol is widely acknowledged to reduce stratospheric ozone through heterogeneous chemistry processes, particularly in polar regions (e.g. Solomon, 1999; Tilmes et al., 2009), and has been studied in earlier GeoMIP activities (e.g. Pitari et al., 2014). Both UKESM1 and CESM2-WACCM6 include detailed stratospheric chemistry and are capable of modelling the impact of stratospheric aerosol on stratospheric ozone (Morgenstern et al., 2009; Mills et al., 2017). The impact of SAI on stratospheric ozone concentrations is shown in Fig. 3.

The SAI-induced changes in ozone concentration between G6solar and G6sulfur are consistent with the distributions of aerosol in the two models. UKESM1, with its higher concentration of aerosol in the tropical reservoir, shows a greater tropical ozone change, with the maximum reduction centred around $20-30 \mathrm{hPa}(\sim 24-27 \mathrm{~km})$ for both models. These changes are consistent with the findings of Tilmes et al. (2018) and are a combination of chemical and transport changes. The reduction in ozone concentrations in the tropics around $20-30 \mathrm{hPa}$ is the result of an increase in vertical advection, while the increase in ozone above this is a result of a decreased rate of catalytic $\mathrm{NO}_{x}$ ozone loss (see Tilmes et al., 2018, for more details). 

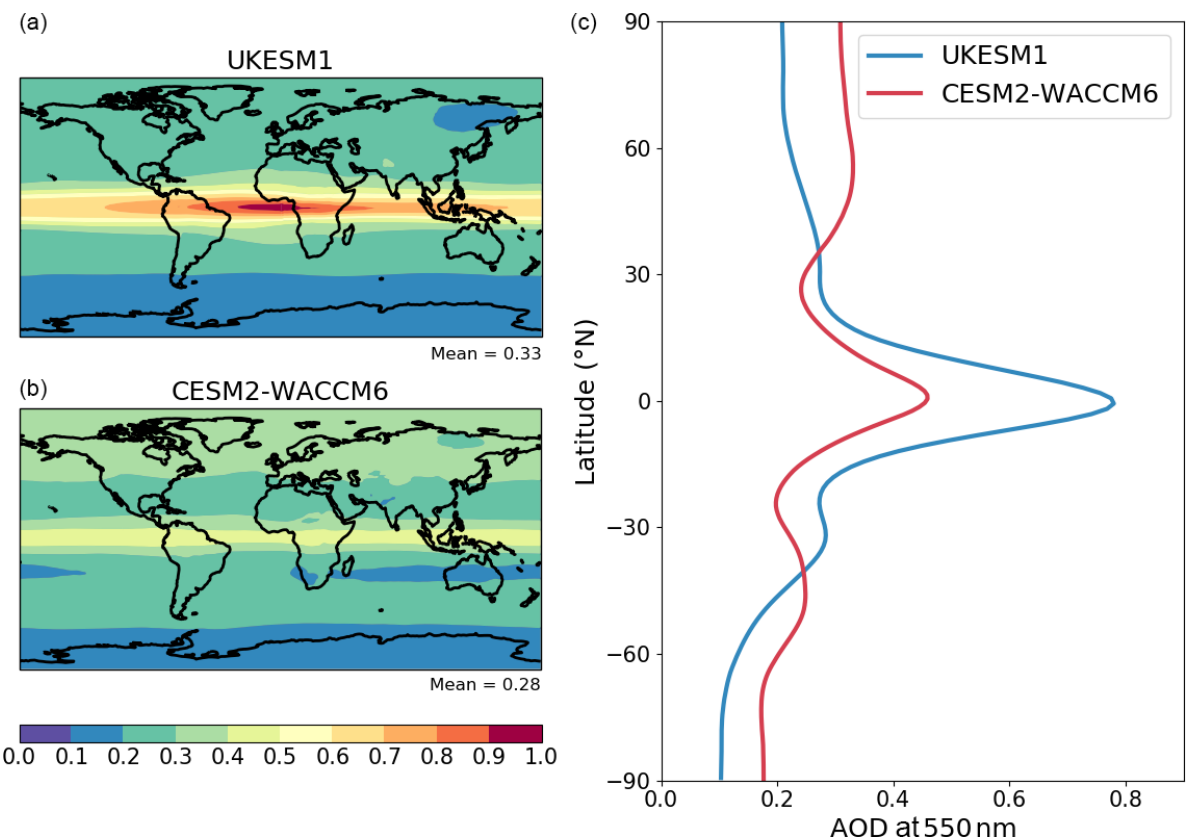

Figure 2. The distribution of the 2081-2100 mean anomaly in annual mean AOD at $550 \mathrm{~nm}$ (dimensionless) due to stratospheric $\mathrm{SO}_{2}$ injection for UKESM1 (a), CESM2-WACCM6 (b) and zonal means for both models (c). The anomaly is calculated from the difference between G6sulfur and G6solar.
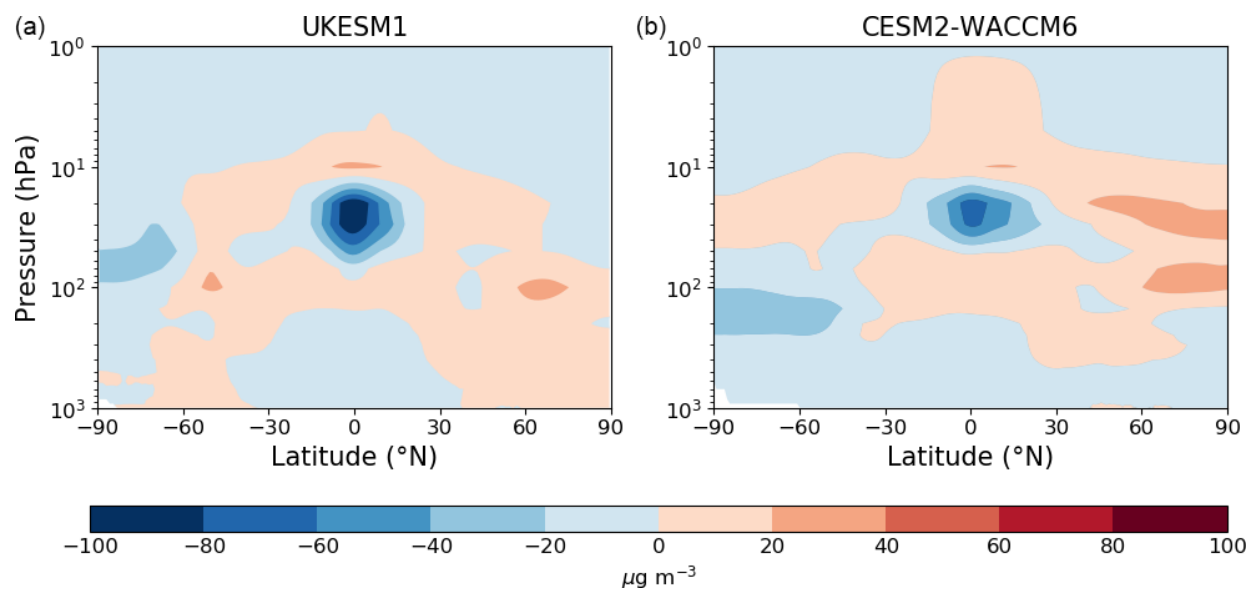

Figure 3. The difference in 2081-2100 annual-mean ozone concentrations $\left(\mu \mathrm{g} \mathrm{m}^{-3}\right.$ ) diagnosed from \{G6sulfur minus G6solar\} for UKESM1 (a) and CESM2-WACCM6 (b).

\subsection{Stratospheric temperature}

Perturbations to stratospheric temperatures are a key mechanism implicated in observed and modelled changes in the Northern Hemisphere wintertime NAO subsequent to stratospheric aerosol injection from volcanoes (e.g. Stenchikov et al., 2002; Lorenz and Hartmann, 2003; Shindell et al., 2004). The annual-mean and the Northern Hemisphere wintertime (December-February) stratospheric temperature perturbations are shown in Fig. 4.

For both models, the peak in the annual-mean temperature perturbation is in the tropics, which is where the $\mathrm{SO}_{2}$ is injected and the resulting stratospheric AOD is greatest (Fig. 2). Differences between the models' aerosol and radiation schemes mean that CESM2-WACCM6 has slightly more warming in the tropical stratosphere despite having somewhat lower AOD compared with UKESM1. Although stratospheric sulfate is primarily a scattering aerosol in the solar part of the spectrum, the small amount of absorption of solar radiation by stratospheric aerosols in the near-infrared, together with absorption of terrestrial longwave radiation, causes the stratospheric heating (e.g. Stenchikov et al., 1998; Jones et al., 2016b). Perturbations to stratospheric tempera- 

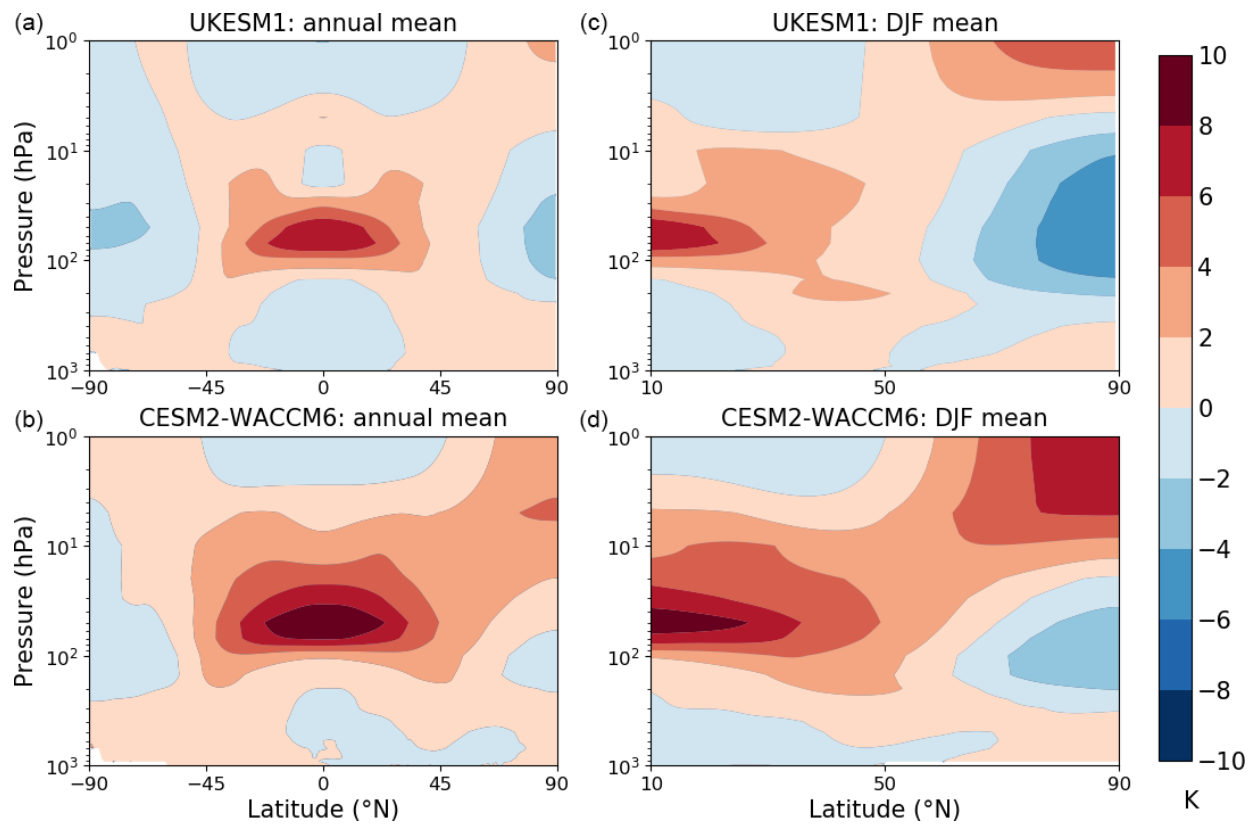

Figure 4. The difference in zonal mean temperature (K) diagnosed from \{G6sulfur minus G6solar\}; panels (a) and (c) show results from UKESM1 and panels (b) and (d) from CESM2-WACCM6. Panels (a) and (b) show global annual-mean results from 2081-2100; panels (c) and (d) show Northern Hemisphere winter (December-February) means over the same period.

tures in the tropics due to less ultraviolet absorption from the reduction of stratospheric ozone (Fig. 3) play a more minor role. The right-hand panels of Fig. 4 show that the impact of solar absorption in the stratosphere cannot be effective during the polar night. This, along with a reduced flux of terrestrial radiation due to low wintertime temperatures, means that stratospheric heating from the aerosol is only present at latitudes south of the Arctic Circle (Shindell et al., 2004). The cooling at high latitudes during Northern Hemisphere winter is consistent with a strengthening of the polar vortex during this period.

\subsection{Wind speed}

\subsubsection{Stratospheric winds}

The effect that the aerosol-induced stratospheric temperature perturbation has on the zonal mean wind speed during Northern Hemisphere winter is shown in Fig. 5.

As in Shindell et al. (2001, their Plate 5), the left-hand panels in Fig. 5 show that in both UKESM1 and CESM2WACCM6 a strong stratospheric zonal mean wind anomaly develops at around $10 \mathrm{hPa}$ at $60-70^{\circ} \mathrm{N}$ with an increase of more than $12 \mathrm{~m} \mathrm{~s}^{-1}$ for UKESM1 and $9 \mathrm{~m} \mathrm{~s}^{-1}$ for CESM2WACCM6, thereby enhancing the strength of the polar vortex. The maximum increase in the zonal wind at this level is centred over Alaska in both models (right-hand panels in Fig. 5).

\subsubsection{Tropospheric winds}

Figure 5 shows the propagation of this enhanced westerly flow to lower levels in the troposphere and to the surface, with both models suggesting an increased westerly flow north of around $50^{\circ} \mathrm{N}$. Figure 6 shows the Northern Hemisphere wintertime zonal mean wind perturbation at $850 \mathrm{hPa}$ induced by SAI for both models.

As with the stratospheric winds, both models show similar behaviour. Both show enhanced $850 \mathrm{hPa}$ winds particularly over the northern Atlantic between the southern tip of Greenland and the UK. This increased westerly flow penetrates into northern Eurasia, indicating that zonal flow is enhanced and shows a strong similarity to the pattern of wind speed perturbation identified in reanalysis data when the polar vortex is strong (e.g. Graf and Walter, 2005).

\subsection{Mean sea-level pressure and NAO index}

As noted in Sect. 1, the NAO may be quantified in terms of the pressure difference between Iceland and the Azores. Here we use December-February mean sea-level pressure (MSLP) from the nearest model grid cell to Stykkishólmur, Iceland $\left(65^{\circ} 05^{\prime} \mathrm{N}, 22^{\circ} 44^{\prime} \mathrm{W}\right)$, and Ponta Delgada in the Azores $\left(37^{\circ} 44^{\prime} \mathrm{N}, 25^{\circ} 41^{\prime} \mathrm{W}\right)$. We also construct an NAO index by removing the long-term mean from the time series of each location's MSLP, normalizing the resulting anomalies by their standard deviation and then taking the difference between the normalized anomalies (e.g. Hurrell, 1995; Rodwell et al., 1999). A positive NAO index indicates when 

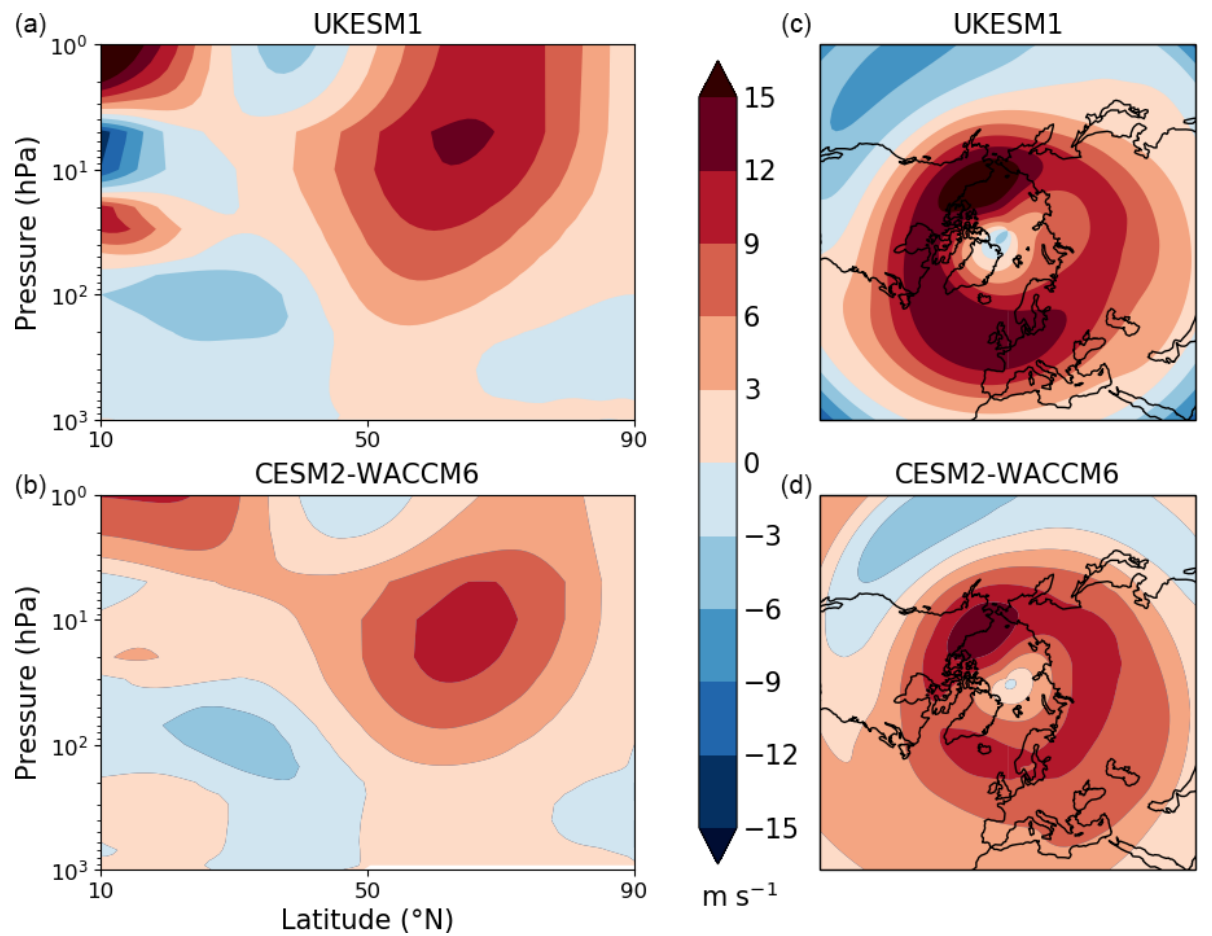

$\mathrm{m} \mathrm{s}^{-1}$

Figure 5. The perturbation to mean December-February zonal wind speed over 2081-2100 (m s ${ }^{-1}$ ) caused by SAI, diagnosed from $\{$ G6sulfur minus G6solar\}. Panels (a) and (b) show the change in Northern Hemisphere zonal wind, with positive values indicating a westerly perturbation and negative values an easterly one. Panels (c) and (d) show the spatial distribution of this change at $10 \mathrm{hPa}$ which is the level of maximum perturbation. Panels (a) and (c) show results from UKESM1, panels (b) and (d) those from CESM2-WACCM6.

(a)

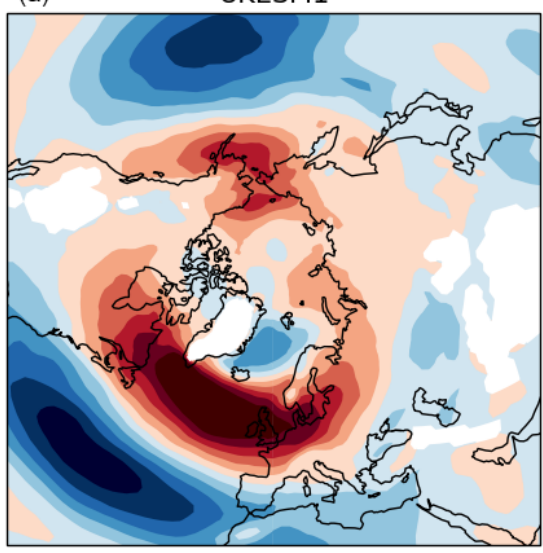

(b)

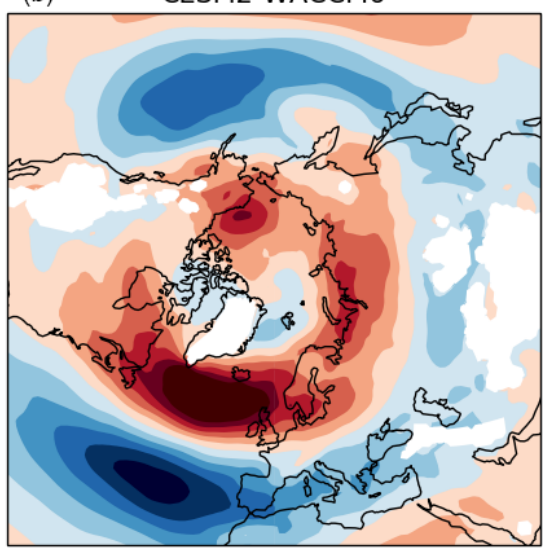

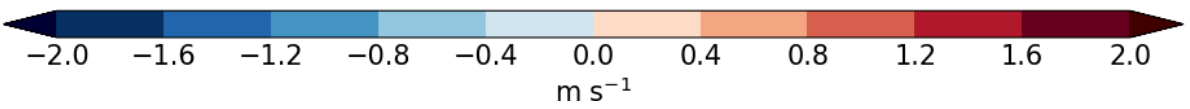

Figure 6. The distribution of the 2081-2100 mean December-February zonal wind speed perturbation due to SAI at $850 \mathrm{hPa}$ (m s${ }^{-1}$ ) for UKESM1 (a) and CESM2-WACCM6 (b). Positive values represent a westerly perturbation and negative values an easterly perturbation; white areas indicate regions where the surface elevation is higher than the mean $850 \mathrm{hPa}$ pressure level. 
the pressure difference between the two stations is greater than normal, and a negative phase indicates when the pressure difference is less than normal. The perturbation to the mean Northern Hemisphere winter surface pressure patterns from SAI is shown in Fig. 7.

Both models show similar large-scale perturbations to MSLP with a vast swath of high-pressure anomalies centred over the Atlantic Ocean at around $50^{\circ} \mathrm{N}$ and to the south of Alaska. The patterns of increased MSLP are broadly similar over Eurasia but are subtly different over the continental USA. A strong area of anomalous low pressure is evident towards the pole in both models, and the strongest pressure gradient anomaly is over the northern Atlantic. This area of strong baroclinicity is associated with the strengthening zonal flow shown in Fig. 6. Over the period 20812100, SAI causes the NAO index in UKESM1 to change from -0.36 in G6solar to +0.73 in G6sulfur. This corresponds to the Azores to Iceland pressure difference increasing from $16.4 \mathrm{hPa}$ (G6solar) to $22.3 \mathrm{hPa}$ (G6sulfur), indicating a strengthening of the NAO of around $+6 \mathrm{hPa}$, which is significant as the standard error due to natural variability is around $1 \mathrm{hPa}$. In CESM2-WACCM6, the NAO index increases from -0.34 (G6solar) to +0.77 (G6sulfur), corresponding to a change in pressure difference of 21.3 to $25.9 \mathrm{hPa}$, indicating a strengthening of around $4.5 \mathrm{hPa}$, which is again significant compared with natural variability.

Before concluding that such impacts on the Northern Hemisphere wintertime NAO are an important difference between end-of-century climates produced by the two different forms of SRM geoengineering, we need to assess if there are any systematic changes in the NAO over the course of the 21 st century in the absence of geoengineering. As noted by Deser et al. (2017), some studies project a slight positive shift in the probability distribution of the NAO phase by the end of the 21 st century. As G6solar and G6sulfur track the temperature evolution of the SSP2-4.5 scenario, we compare 20812100 means from each model's CMIP6 ssp245 simulation with present day (PD, 2011-2030) means constructed from each model's CMIP6 historical and ssp245 experiments. In UKESM1 the change in Azores-to-Iceland pressure difference between PD and 2081-2100 in SSP2-4.5 is 17.6 to $17.7 \mathrm{hPa}$ (NAO index essentially unchanged at +0.19 ), and in CESM2-WACCM6 the corresponding values are 21.3 to $19.8 \mathrm{hPa}$ (NAO index change -0.26 to -0.63 ). It is therefore clear that the impact of SAI geoengineering on the Northern Hemisphere wintertime NAO dominates over any effects due to global warming over this period.

\subsection{Regional mid-latitude temperature}

We have seen that both models simulate the impact of SAI by inducing a positive phase of the NAO with both models showing similar patterns of response in stratospheric heating, stratospheric and tropospheric winds, and MSLP. We now briefly examine the impact of SAI on near-surface tem- peratures by looking at the difference between G6sulfur and G6solar during the Northern Hemisphere wintertime with a focus on the continental scale. To put these changes in context, by experimental design the temperature changes in all experiments compared with present day (PD) show the expected warming of climate commensurate with the SSP24.5 scenario (annual-mean changes from PD to 2081-2100 shown in Fig. 1). The purpose of examining regional changes in temperature is to emphasize that despite the inter-model similarity of response of many dynamical features associated with the NAO, there are considerable inter-model differences in the resulting regional temperatures in some areas.

Both models indicate that SAI induces broad-scale patterns of temperature perturbation over Eurasia during Northern Hemisphere winter resembling those associated with a positive phase of the NAO observed subsequent to large tropical volcanic eruptions (Shindell et al., 2004), i.e. a warming to the north and a cooling to the south of $\sim 50^{\circ} \mathrm{N}$ (Fig. 8). Explosive volcanic eruptions provide a very useful, albeit imperfect, analogue for stratospheric aerosol injection geoengineering (Robock et al., 2013). The facts that similar temperature patterns are observed following explosive volcanic eruptions and that the proposed mechanisms for impacting the strength of the NAO are identical for volcanic and geoengineering cases suggest that the inducing of positive phases of the NAO under SAI geoengineering is a relatively robust conclusion.

While there are similarities in the broad-scale hemispheric pattern of temperature perturbations, over continental North America the models suggest rather different regional temperature responses. In UKESM1 the induced positive phase of the NAO from SAI leads to a warming of the eastern side of the continent as observed (Shindell et al., 2004) as well as over the north-western Atlantic, while CESM2WACCM6 suggests a general cooling across the continent with only the warm anomaly over the North Atlantic being evident. This cooling in CESM2-WACCM6 is consistent with the high-pressure anomaly across the whole continent in this model (Fig. 7), which would enhance advection of cold air from higher latitudes. In contrast, UKESM1 has a low-pressure anomaly over much of continental North America, which would have the opposite tendency. It is generally accepted that Northern Hemisphere wintertime conditions over the eastern USA are anomalously warm during the positive phase of the NAO (e.g. http://climate.ncsu.edu/ images/edu/NAO2.jpg, last access: 22 January 2021) which perhaps indicates that UKESM1 may reproduce this phase of the NAO with greater fidelity. In contrast, however, CESM2WACCM6 seems to better represent the cooling observed at high latitudes over North America following large volcanic eruptions. Significant cooling is also observed over northern Africa following such eruptions with cold anomalies extending to around $10^{\circ} \mathrm{N}$ (Shindell et al., 2004). Both models show cool anomalies in this region but they extend further south in 
(a)

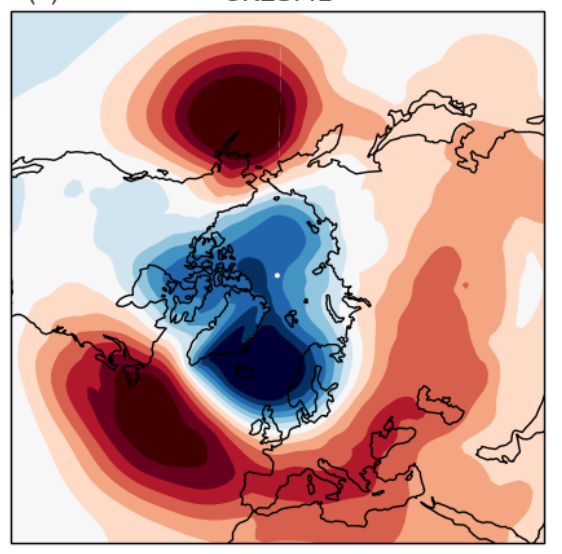

(b) CESM2-WACCM6

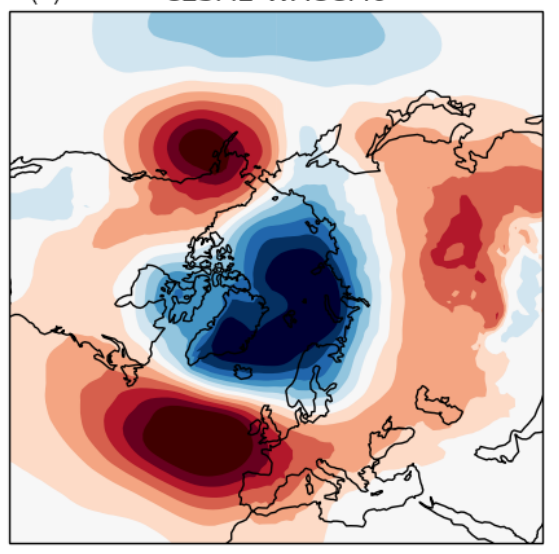

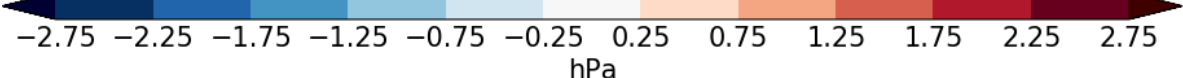

Figure 7. The change induced by SAI in 2081-2100 mean December-February MSLP (hPa) for UKESM1 (a) and CESM2-WACCM6 (b) diagnosed from \{G6sulfur minus G6solar\}.
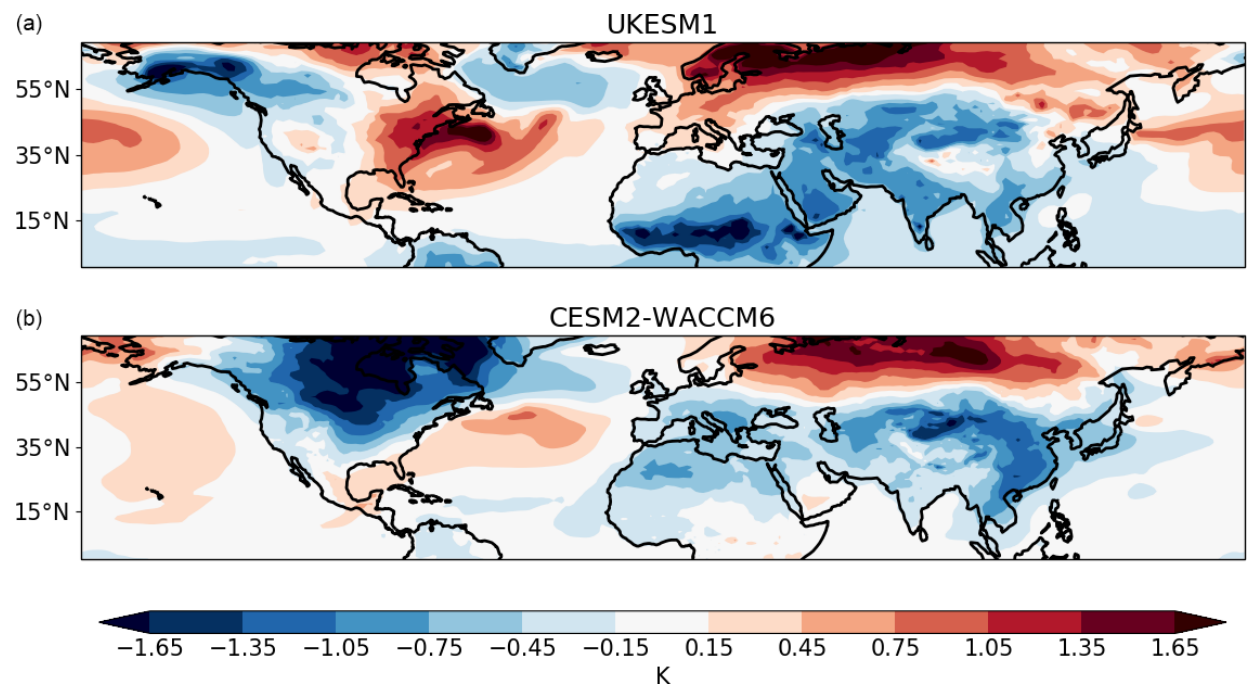

Figure 8. The perturbation to 2081-2100 mean December-February near-surface air temperature (K) induced by SAI diagnosed from \{G6sulfur minus G6solar\} for UKESM1 (a) and CESM2-WACCM6 (b). The area plotted is chosen to replicate that presented by Shindell et al. (2004, their Fig. 2).

UKESM1 compared with CESM2-WACCM6, suggesting a somewhat weaker response to SAI in the latter model.

\subsection{Regional mid-latitude precipitation}

Over Europe, while the models exhibit some differences in the exact demarcation between increased precipitation over northern Europe and Scandinavia and decreased precipitation over southern Europe (Fig. 9), the general patterns are clearly in line with observations during positive phases of the NAO. For example, Fowler and Kilsby (2002) and Burt and Howden (2013) investigated precipitation anomalies in northern areas of the UK and concluded that precipitation and streamflow is considerably enhanced during positive phases of the NAO. On larger scales, López-Moreno et al. (2008) and Casanueva et al. (2014) conclude that, during the positive phase of the NAO, positive precipitation anomalies occur over northern Europe while negative precipitation anomalies occur over southern Europe. Furthermore, the study of Zanardo et al. (2019) indicates that the NAO clearly correlates with the occurrence of catastrophic floods across Europe (and the associated economic losses) and that over northern Eu- 
rope the majority of historic winter floods occurred during a positive NAO phase.

Over North America, both models are consistent and indicate an increase in wintertime precipitation, which is again consistent with observations of wintertime precipitation anomalies during the positive phase of the NAO. There are fewer quantitative studies of the impacts of the NAO over North America as the social and economic costs are not so readily apparent as over Europe. However, an analysis by Durkee et al. (2008) indicates positive anomalies of rain over south-eastern states and positive anomalies of snowfall over north-eastern states during positive phases of the NAO.

\subsection{Contextualizing in terms of changes compared with present-day precipitation}

We have shown that the SAI-induced response of the NAO and the associated impacts on precipitation are relatively well understood and reasonably consistent between the two models. As in earlier modelling and observational studies, the impact is particularly marked over Europe, with northern Europe experiencing enhanced precipitation and southern Europe reduced precipitation. We therefore focus our attention on the magnitude of the SAI-induced feedbacks on precipitation from the positive NAO anomaly compared with the temperature- and circulation-induced feedbacks on precipitation from global warming over the European area. We do this by comparing end-of-century (2081-2100) precipitation in UKESM1 and CESM2-WACCM6 with that from the present day (PD, 2011-2030) for the ssp585, ssp245, G6solar and G6sulfur simulations (Fig. 10 for UKESM1 and Fig. 11 for CESM2-WACCM6).

As expected, Fig. 10 shows that the precipitation changes in 2081-2100 compared with PD are significantly less in ssp245 than in ssp585. North of $50^{\circ} \mathrm{N}$ there are many areas in ssp585 that experience a change in precipitation exceeding $+0.5 \mathrm{~mm} \mathrm{~d}^{-1}$, while south of $45^{\circ} \mathrm{N}$ areas tend to be drier than in PD; these patterns are consistent with the patterns of precipitation and runoff changes in multi-model climate change simulation assessments (Kirtman et al., 2013; Guerreiro et al., 2018). When comparing the future precipitation response in G6sulfur to that in ssp245, it is evident that the precipitation anomaly pattern from the NAO-induced feedback (Fig. 9) acts to reinforce the temperature-induced precipitation feedback. Compared with ssp245, the precipitation anomaly in G6sulfur is more positive in northern Europe and more negative in southern Europe, with a negative anomaly that encompasses the area all around the Black Sea. When comparing the future precipitation response in G6sulfur with G6solar, it is evident that while the precipitation increases north of around $50^{\circ} \mathrm{N}$ show some consistency between the two, there is no such agreement further south. Over Iberia, Italy, the Balkans, Greece, Turkey, Ukraine and southern Russia the precipitation anomalies show a wintertime precipitation decrease in G6sulfur but an increase in G6solar. It is therefore evident that the idealized approach of G6solar does not adequately represent the regional impacts on precipitation over Europe.

Generally, the conclusions from UKESM1 presented in Fig. 10 are supported by the results from CESM2-WACCM6 (Fig. 11). The strong signal of increased precipitation in northern Europe evident in ssp585 is reduced in ssp245, G6solar and G6sulfur. G6sulfur again shows a greater reduction in precipitation south of about $45^{\circ} \mathrm{N}$ when compared with G6solar. The implications of these findings are discussed in more detail in the following section.

\section{Discussion and Conclusions}

Using data from two Earth system models, we have compared the final 20 years from two numerical experiments which employ different representations of geoengineering in a scenario where the amount of cooling generated is the same. The G6solar experiment achieves the required cooling by the highly idealized method of reducing the solar constant over the course of the 21st century, while the G6sulfur experiment achieves the same degree of cooling by injecting increasing amounts of $\mathrm{SO}_{2}$ into the tropical lower stratosphere (SAI geoengineering). Comparing the results from the two experiments should help cast light on geoengineering impacts which only become evident when the method of geoengineering is represented with some fidelity.

Although both models' SAI simulations are successful in cooling from SSP5-8.5 to SSP2-4.5 levels, the resulting perturbations to the AOD distribution are by no means identical. Differences far larger than these have been reported in earlier coordinated GeoMIP simulations. Pitari et al. (2014, their Fig. 3d) indicate that some models (e.g. GEOSCCM) perform similarly to UKESM1 in maintaining a peak AOD of 3 times that at mid-latitudes in the tropical reservoir, while other models (e.g. GISS-E2-R) show almost the opposite behaviour with a peak AOD twice that in the tropical reservoir at mid-latitudes. Pitari et al. (2014) caution that aspects of the performance of these two models are hampered by the lack of explicit treatment of heterogeneous chemistry (GISSE2-R) and the lack of impact of the stratospheric aerosol on photolysis rates (GEOSCCM); these caveats do not apply to the UKESM1 and CESM2-WACCM6 models, which include these processes.

The results from both models indicate that a key impact of tropical SAI geoengineering is the generation of a persistent positive phase of the NAO during Northern Hemisphere wintertime. The intensification of the stratospheric jet produces an increase in surface zonal winds over the North Atlantic, leading to a warming of the Eurasian continent northwards of about $50^{\circ} \mathrm{N}$ and the associated risks of flooding in northern European regions (e.g. Scaife et al., 2008). The mechanism for generating these anomalies appears to be the same as that observed following large explosive volcanic eruptions 

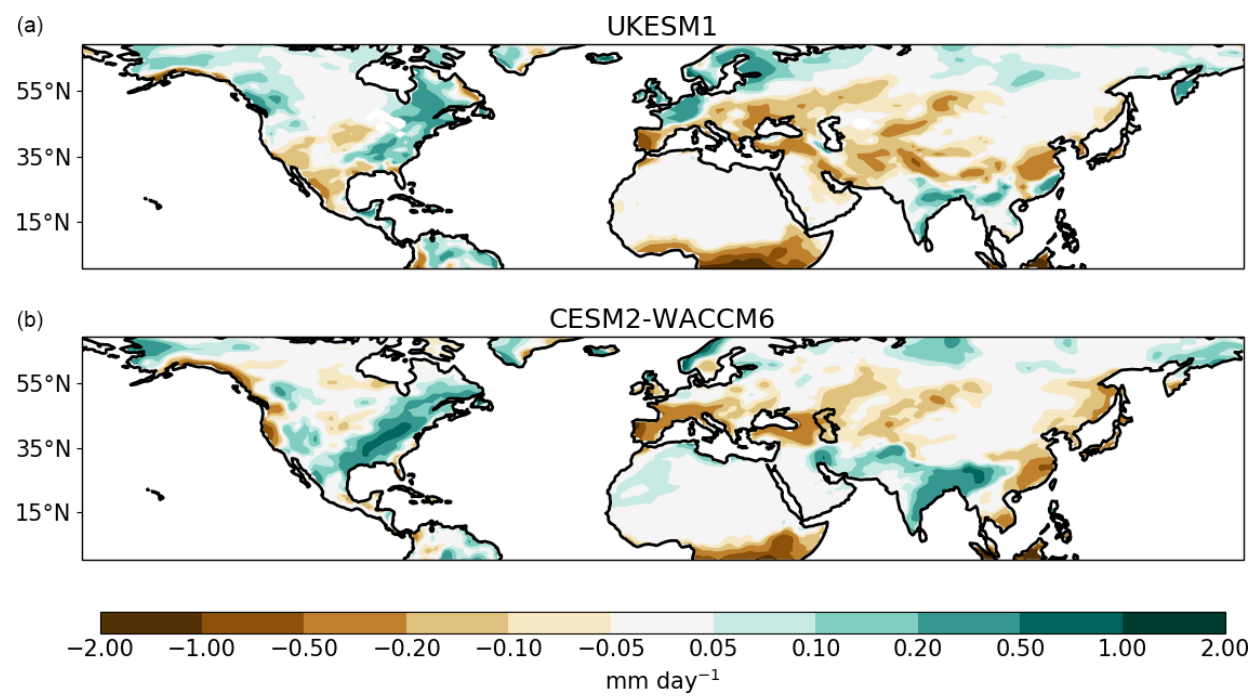

Figure 9. The perturbation to 2081-2100 mean December-February land precipitation rate ( $\mathrm{mm} \mathrm{d}^{-1}$ ) induced by SAI diagnosed from \{G6sulfur minus G6solar\} for UKESM1 (a) and CESM2-WACCM6 (b).
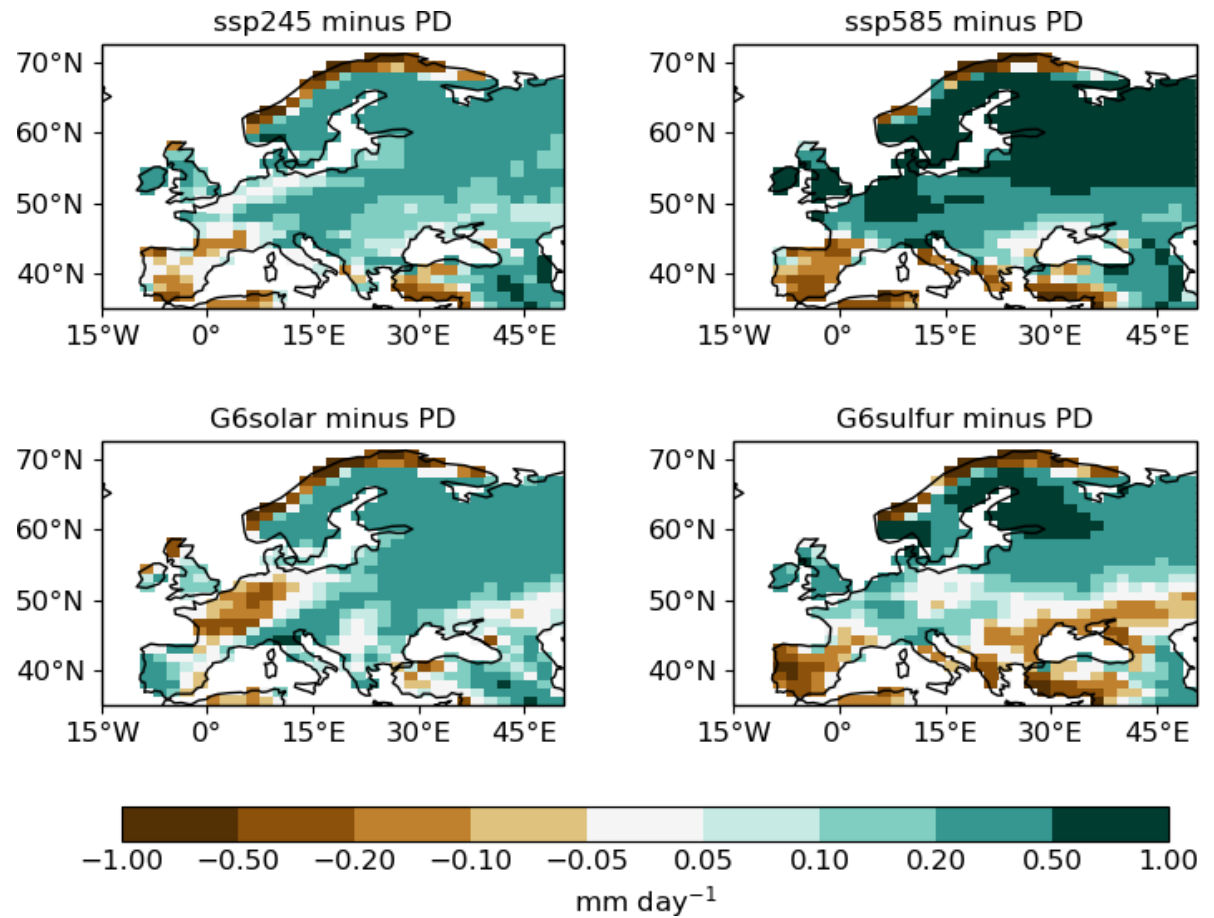

Figure 10. Changes in mean December-February land precipitation rate ( $\mathrm{mm} \mathrm{d}^{-1}$ ) between present day (PD, 2011-2030) and 2081-2100 in experiments ssp245, ssp585, G6solar and G6sulfur in UKESM1. PD means are constructed in the same manner as in Fig. 1.

in the tropics. This is consistent with the form of SAI simulated in G6sulfur being essentially equivalent to a continuous, large volcanic eruption in the tropics and indicates that the response to any putative, continuous large-scale $\mathrm{SO}_{2}$ injection is likely to be the same as that which has been suggested to follow large sporadic eruptions.

In terms of impacts, the end-of-century (2081-2100) European wintertime precipitation anomalies in ssp585, ssp245,
G6solar and G6sulfur provide an example relating to a critical argument that has been circulating in the geoengineering community for over a decade: that of winners and losers (e.g. Irvine et al., 2010; Kravitz et al., 2014). While few would argue against the benefits of ameliorating the changes in wintertime precipitation under SSP $5-8.5$ by following the SSP2-4.5 scenario (Figs. 10 and 11), the situation is different when examining the changes seen in G6sulfur. For exam- 

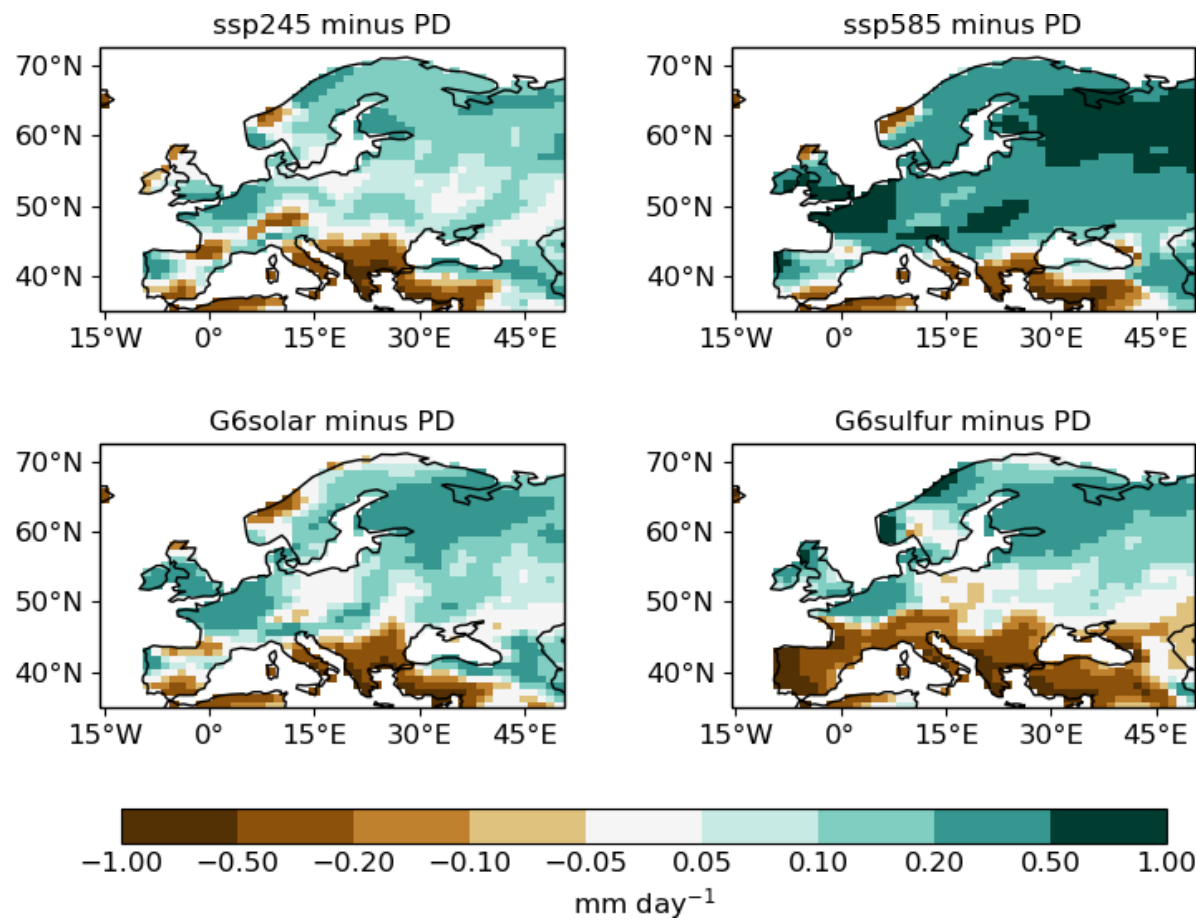

Figure 11. Same as Fig. 10 but for CESM2-WACCM6.

ple, when taking the results from CESM2-WACCM6 at face value, one might argue that the impacts of the wintertime drying of vast swathes of the European continent surrounding the Mediterranean Sea (Fig. 11) might be more damaging in terms of their impact on biodiversity, ecology and peoples' lives than the impact of increased flood risk in northern Europe under even the extreme SSP5-8.5 scenario. Of course, here we are limited to analysing the results from just two Earth system models which take no account of trying to tailor the injection strategy to minimize residual climate impacts (e.g. MacMartin et al., 2013), and studies have shown that SAI can ameliorate many regional impacts of climate change (e.g. Jones et al., 2018). Nevertheless, the impact of the SAI-induced effects on the NAO indicate the need for detailed modelling of geoengineering processes when considering the potential regional impacts of such actions. Studies which have investigated the issue of geoengineering winners and losers have generally studied results from idealized solar reduction approaches to geoengineering and therefore may have missed some of the effects shown here. The differences in regional response over the continental USA and Africa (e.g. Fig. 8) demonstrate that inter-model uncertainty remains and indicate that more models need to perform these simulations before any conclusions regarding potential continental-scale climate change under SRM are drawn.

In addition to the potential climate impacts from SAI shown here, such intervention would produce many other benefits and risks (e.g. Robock, 2020). Some of these additional risks are related not only to the physical climate system but also deal with governance, unknowns, ethics and aesthetics. Furthermore, the technology to inject sulfur into the stratosphere does not currently exist. Before any decision by society to start climate intervention, much more work is needed to quantify all these potential benefits and risks. In the meantime, even if some climate intervention is used for a time, there remains a great deal of work on mitigation and adaptation to address the threat of global warming.

Code availability. Due to intellectual property rights restrictions, we cannot provide either the source code or documentation papers for the Met Office Unified Model. The UM is available for use under licence - for further information on how to apply for a licence, see http://www.metoffice.gov.uk/research/ modelling-systems/unified-model (last access: 23 July 2020). Previous and current Community Earth System Model (CESM) versions are freely available at http://www.cesm.ucar.edu/models/ cesm2 (last access: 23 July 2020).

Data availability. The simulation data used in this study are archived on the Earth System Grid Federation (ESGF) (https:// esgf-node.llnl.gov/projects/cmip6, last access: 23 July 2020). The model source IDs are UKESM1-0-LL for UKESM1 and CESM2WACCM for CESM2-WACCM6.

Author contributions. AJ and JMH led the analysis and wrote the article with contributions from ACJ, ST, BK and AR. The UKESM1 
and CESM2-WACCM6 simulations were carried out by AJ and ST, respectively. BK was central in coordinating the GeoMIP6 activity.

Competing interests. The authors declare that they have no conflict of interest.

Acknowledgements. Andy Jones would like to thank the Met Office team responsible for the managecmip software which greatly simplified the work involved. Andy Jones and Jim M. Haywood were supported by the Met Office Hadley Centre Climate Programme funded by the UK Government Department for Business, Energy and Industrial Strategy (BEIS) and the UK Government Department for Environment, Food and Rural Affairs (Defra). The CESM project is supported primarily by the US National Science Foundation (NSF). Some of the material is based upon work supported by the National Center for Atmospheric Research (NCAR) which is a major facility sponsored by the NSF. Computing and data storage resources for CESM, including the Cheyenne supercomputer (https://doi.org/10.5065/D6RX99HX), were provided by the Computational and Information Systems Laboratory (CISL) at NCAR. Support for Ben Kravitz was provided in part by the NSF, the Indiana University Environmental Resilience Institute and the Prepared for Environmental Change Grand Challenge initiative. The Pacific Northwest National Laboratory is operated for the US Department of Energy by Battelle Memorial Institute. Alan Robock is supported by the NSF. We acknowledge the World Climate Research Programme which, through its Working Group on Coupled Modelling, coordinated and promoted CMIP. We thank the climate modelling groups for producing and making available their model output, ESGF for archiving the data and providing access, and the multiple funding agencies that support CMIP6 and ESGF. We also thank all participants of the Geoengineering Model Intercomparison Project and their model development teams.

Financial support. This research has been supported by the Department for Business, Energy and Industrial Strategy, UK Government, the Department for Environment, Food and Rural Affairs, UK Government, the US National Science Foundation under cooperative agreement 1852977, agreement CBET-1931641 and grant AGS-2017113, the US National Center for Atmospheric Research, the Indiana University Environmental Resilience Institute and the Prepared for Environmental Change Grand Challenge initiative.

Review statement. This paper was edited by Peter Haynes and reviewed by two anonymous referees.

\section{References}

Andrews, T., Andrews, M. B., Bodas-Salcedo, A., Jones, G. S., Kuhlbrodt, T., Manners, J., Menary, M. B., Ridley, J., Ringer, M. A., Sellar, A. A., and Senior, C. A.: Forcings, feedbacks, and climate sensitivity in HadGEM3-GC3.1 and UKESM1, J. Adv. Model. Earth Sy., 11, 4377-4394, https://doi.org/10.1029/2019MS001866, 2019.

Archibald, A. T., O'Connor, F. M., Abraham, N. L., ArcherNicholls, S., Chipperfield, M. P., Dalvi, M., Folberth, G. A., Dennison, F., Dhomse, S. S., Griffiths, P. T., Hardacre, C., Hewitt, A. J., Hill, R. S., Johnson, C. E., Keeble, J., Köhler, M. O., Morgenstern, O., Mulcahy, J. P., Ordóñez, C., Pope, R. J., Rumbold, S. T., Russo, M. R., Savage, N. H., Sellar, A., Stringer, M., Turnock, S. T., Wild, O., and Zeng, G.: Description and evaluation of the UKCA stratosphere-troposphere chemistry scheme (StratTrop vn 1.0) implemented in UKESM1, Geosci. Model Dev., 13, 1223-1266, https://doi.org/10.5194/gmd-13-1223-2020, 2020.

Best, M. J., Pryor, M., Clark, D. B., Rooney, G. G., Essery, R. L. H., Ménard, C. B., Edwards, J. M., Hendry, M. A., Porson, A., Gedney, N., Mercado, L. M., Sitch, S., Blyth, E., Boucher, O., Cox, P. M., Grimmond, C. S. B., and Harding, R. J.: The Joint UK Land Environment Simulator (JULES), model description Part 1: Energy and water fluxes, Geosci. Model Dev., 4, 677-699, https://doi.org/10.5194/gmd-4-677-2011, 2011.

Burt, T. P. and Howden, N. J. K.: North Atlantic Oscillation amplifies orographic precipitation and river flow in upland Britain, Water Resour. Res., 49, 3504-3515, https://doi.org/10.1002/wrcr.20297, 2013.

Casanueva, A., Rodríguez-Puebla, C., Frías, M. D., and GonzálezReviriego, N.: Variability of extreme precipitation over Europe and its relationships with teleconnection patterns, Hydrol. Earth Syst. Sci., 18, 709-725, https://doi.org/10.5194/hess-18709-2014, 2014.

Da-Allada, C. Y., Balö̈tcha, E., Alamou, E. A., Awo, F. M., Bonou, F., Pomalegni, Y., Biao, E. I., Obada, E., Zandagba, J. E., Tilmes, S., and Irvine, P. J.: Changes in West African summer monsoon precipitation under stratospheric aerosol geoengineering, Earths Future, 8, e2020EF001595, https://doi.org/10.1029/2020EF001595, 2020.

Danabasoglu, G., Bates, S. C., Briegleb, B. P., Jayne, S. R., Jochum, M., Large, W. G., Peacock, S., and Yeager, S. G.: The CCSM4 Ocean Component, J. Climate, 25, 1361-1389, https://doi.org/10.1175/JCLI-D-11-00091.1, 2012.

Danabasoglu, G., Lamarque, J.-F., Bacmeister, J., Bailey, D. A., DuVivier, A. K., Edwards, J., Emmons, L. K., Fasullo, J., Garcia, R., Gettelman, A., Hannay, C., Holland, M. M., Large, W. G., Lauritzen, P. H., Lawrence, D. M., Lenaerts, J. T. M., Lindsay, K., Lipscomb, W. H., Mills, M. J., Neale, R., Oleson, K. W., Otto-Bliesner, B., Phillips, A. S., Tilmes, S., van Kampenhout, L., Vertenstein, M., Bertini, A., Dennis, J, Deser, C., Fischer, C., Fox-Kemper, B., Kay, J. E., Kinnison, D., Kushner, P. J., Larson, V. E., Long, M. C., Mickelson, S., Moore, J. K., Nienhouse, E., Polvani, L., Rasch, P. J., and Strand, W. G.: The Community Earth System Model Version 2 (CESM2), J. Adv. Model. Earth Sy., 12, e2019MS001916, https://doi.org/10.1029/2019MS001916, 2020.

Deser, C., Hurrell, J. W., and Phillips, A. S.: The role of the North Atlantic Oscillation in European climate projections, Clim. Dynam., 49, 3141-3157, https://doi.org/10.1007/s00382-016-3502z, 2017.

Dhomse, S. S., Emmerson, K. M., Mann, G. W., Bellouin, N., Carslaw, K. S., Chipperfield, M. P., Hommel, R., Abraham, N. L., Telford, P., Braesicke, P., Dalvi, M., Johnson, C. E., O’Connor, F., Morgenstern, O., Pyle, J. A., Deshler, T., Za- 
wodny, J. M., and Thomason, L. W.: Aerosol microphysics simulations of the Mt. Pinatubo eruption with the UM-UKCA composition-climate model, Atmos. Chem. Phys., 14, 1122111246, https://doi.org/10.5194/acp-14-11221-2014, 2014.

Dickinson, R. E.: Climate engineering a review of aerosol approaches to changing the global energy balance, Climatic Change, 33, 279-290, https://doi.org/10.1007/BF00142576, 1996.

Dunstone, N., Smith, D., Scaife, A., Hermanson, L., Eade, R., Robinson, N., Andrews, M., and Knight, J.: Skilful predictions of the winter North Atlantic Oscillation one year ahead, Nat. Geosci., 9, 809-814, https://doi.org/10.1038/NGEO2824, 2016.

Durkee, J. D., Frye, J. D., Fuhrmann, C. M., Lacke, M. C., Jeong, H. G., and Mote, T. L.: Effects of the North Atlantic Oscillation on precipitation-type frequency and distribution in the eastern United States, Theor. Appl. Climatol., 94, 51-65, https://doi.org/10.1007/s00704-007-0345-x, 2008.

Eyring, V., Bony, S., Meehl, G. A., Senior, C. A., Stevens, B., Stouffer, R. J., and Taylor, K. E.: Overview of the Coupled Model Intercomparison Project Phase 6 (CMIP6) experimental design and organization, Geosci. Model Dev., 9, 1937-1958, https://doi.org/10.5194/gmd-9-1937-2016, 2016.

Forster, P., Ramaswamy, V., Artaxo, P., Berntsen, T., Betts, R., Fahey, D. W., Haywood, J., Lean, J., Lowe, D. C., Myhre, G., Nganga, J., Prinn, R., Raga, G., Schulz, M., and Van Dorland, R.: Changes in Atmospheric Constituents and in Radiative Forcing, in: Climate Change 2007: The Physical Science Basis. Contribution of Working Group I to the Fourth Assessment Report of the Intergovernmental Panel on Climate Change, edited by: Solomon, S., Qin, D., Manning, M., Chen, Z., Marquis, M., Averyt, K. B., Tignor, M., and Miller, H. L., Cambridge University Press, Cambridge, United Kingdom and New York, USA, 2007.

Fowler, H. J. and Kilsby, C. G.: Precipitation and the North Atlantic Oscillation: a study of climatic variability in northern England, Int. J. Climatol., 22, 843-866, https://doi.org/10.1002/joc.765, 2002.

Guerreiro, S. B., Dawson, R. J., Kilsby, C., Lewis, E., and Ford, A.: Future heat-waves, droughts and floods in 571 European cities, Environ. Res. Lett., 13, 034009, https://doi.org/10.1088/17489326/aaaad3, 2018.

Gettelman, A., Mills, M. J., Kinnison, D. E., Garcia, R. R., Smith, A. K., Marsh, D. R., Tilmes, S., Vitt, F., Bardeen, C. G., McInerny, J., Liu, H.-L., Solomon, S. C., Polvani, L. M., Emmons, L. K., Lamarque, J.-F., Richter, J. H., Glanville, A. S., Bacmeister, J. T., Phillips, A. S., Neale, R. B., Simpson, I. R., DuVivier, A. K., Hodzic, A., and Randel, W. J.: The Whole Atmosphere Community Climate Model Version 6 (WACCM6), J. Geophys. Res., 124, 12380-12403, https://doi.org/10.1029/2019JD030943, 2019a.

Gettelman, A., Hannay, C., Bacmeister, J. T., Neale, R. B., Pendergrass, A. G., Danabasoglu, G., Lamarque, J.-F., Fasullo, J. T., Bailey, D. A., Lawrence, D. M., and Mills, M. J.: High climate sensitivity in the Community Earth System Model Version 2 (CESM2), Geophys. Res. Lett., 46, 8329-8337, https://doi.org/10.1029/2019GL083978, 2019b.

Graf, H.-F., Perlwitz, J., and Kirchner, I.: Northern Hemisphere tropospheric mid-latitude circulation after violent volcanic eruptions, Contr. Atmos. Phys., 67, 3-13, 1994.
Graf, H.-F. and Walter, K.: Polar vortex controls coupling of North Atlantic Ocean and atmosphere, Geophys. Res. Lett., 32, L01704, https://doi.org/10.1029/2004GL020664, 2005.

Grant, W. B., Browell, E. V., Long, C. S., Stowe, L. L., Grainger, R. G., and Lambert, A.: Use of volcanic aerosols to study the tropical stratospheric reservoir, J. Geophys. Res., 101, 3973-3988, https://doi.org/10.1029/95JD03164, 1996.

Gray, L. J., Scaife, A. A., Mitchell, D. M., Osprey, S., Ineson, S., Hardiman, S., Butchart, N., Knight, J. R., Sutton, R., and Kodera, $\mathrm{K}$.: A lagged response to the 11 year solar cycle in observed winter Atlantic/European weather patterns, J. Geophys. Res., 118, 13405-13420, https://doi.org/10.1002/2013JD020062, 2013.

Guo, S., Bluth, G. S., Rose, W. I., Watson, I. M., and Prata, A. J.: Re-evaluation of the $\mathrm{SO}_{2}$ release of the 15 June 1991 Pinatubo eruption using ultraviolet and infrared satellite sensors, Geochem. Geophys. Geosys., 5, Q04001, https://doi.org/10.1029/2003GC000654, 2004.

Haywood, J. M., Jones, A., Clarisse, L., Bourassa, A., Barnes, J., Telford, P., Bellouin, N., Boucher, O., Agnew, P., Clerbaux, C., Coheur, P., Degenstein, D., and Braesicke, P.: Observations of the eruption of the Sarychev volcano and simulations using the HadGEM2 climate model, J. Geophys. Res., 115, D21212, https://doi.org/10.1029/2010JD014447, 2010.

Haywood, J. M., Jones, A., and Jones, G. S.: The impact of volcanic eruptions in the period 2000-2013 on global mean temperature trends evaluated in the HadGEM2-ES climate model, Atmos. Sci. Lett., 15, 92-96. https://doi.org/10.1002/as12.471, 2013.

Hunke, E. C., Lipscomb, W. H., Turner, A. K., Jeffery, N., and Elliott, S.: CICE: The Los Alamos Sea Ice Model. Documentation and Software User's Manual. Version 5.1, T-3 Fluid Dynamics Group, Los Alamos National Laboratory, Tech. Rep. LA-CC-06$012,2015$.

Hurrell, J. W.: Decadal trends in the North Atlantic Oscillation: regional temperatures and precipitation, Science, 269, 676-679, https://doi.org/10.1126/science.269.5224.676, 1995.

Ineson, S., Scaife, A. A., Knight, J. R., Manners, J. C., Dunstone, N. J., Gray, L. J., and Haigh, J. D.: Solar forcing of winter climate variability in the Northern Hemisphere, Nat. Geosci., 4, 753-757, https://doi.org/10.1038/ngeo1282, 2011.

Irvine, P., Ridgwell, A., and Lunt, D. J.: Assessing the regional disparities in geoengineering impacts, Geophys. Res. Lett., 37, L18702, https://doi.org/10.1029/2010GL044447, 2010.

Irvine, P., Emanuel, K., He, J., Horowitz, L. W., Vecchi, G., and Keith, D.: Halving warming with idealized solar geoengineering moderates key climate hazards, Nat. Clim. Change, 9, 295-299, https://doi.org/10.1038/s41558-019-0398-8, 2019.

Jones, A., Haywood, J., Boucher, O., Kravitz, B., and Robock, A.: Geoengineering by stratospheric $\mathrm{SO}_{2}$ injection: results from the Met Office HadGEM2 climate model and comparison with the Goddard Institute for Space Studies ModelE, Atmos. Chem. Phys., 10, 5999-6006, https://doi.org/10.5194/acp10-5999-2010, 2010.

Jones, A. C., Haywood, J. M., Jones, A., and Aquila, V.: Sensitivity of volcanic aerosol dispersion to meteorological conditions: A Pinatubo case study, J. Geophys. Res., 121, 6892-6908, https://doi.org/10.1002/2016JD025001, 2016a.

Jones, A. C., Haywood, J. M., and Jones, A.: Climatic impacts of stratospheric geoengineering with sulfate, black car- 
bon and titania injection, Atmos. Chem. Phys., 16, 2843-2862, https://doi.org/10.5194/acp-16-2843-2016, 2016b.

Jones, A. C., Haywood, J. M., Dunstone, N., Emanuel, K., Hawcroft, M. K., Hodges, K. I., and Jones, A.: Impacts of hemispheric solar geoengineering on tropical cyclone frequency, Nat. Commun., 8, 1382, https://doi.org/10.1038/s41467-017-016060, 2017.

Jones, A. C., Hawcroft, M. K., Haywood, J. M., Jones, A., Guo, X., and Moore, J. C.: Regional climate impacts of stabilizing global warming at $1.5 \mathrm{~K}$ using solar geoengineering, Earths Future, 6, 230-251, https://doi.org/10.1002/2017EF000720, 2018.

Kirtman, B., Power, S. B., Adedoyin, J. A., Boer, G. J., Bojariu, R., Camilloni, I., Doblas-Reyes, F. J., Fiore, A. M., Kimoto, M., Meehl, G. A., Prather, M., Sarr, A., Schär, C., Sutton, R., van Oldenborgh, G. J., Vecchi G., and Wang, H. J.: Near-term Climate Change: Projections and Predictability, in: Climate Change 2013: The Physical Science Basis. Contribution of Working Group I to the Fifth Assessment Report of the Intergovernmental Panel on Climate Change, edited by: Stocker, T. F., Qin, D., Plattner, G.-K., Tignor, M., Allen, S. K., Boschung, J., Nauels, A., Xia, Y., Bex, V., and Midgley, P. M., Cambridge University Press, Cambridge, United Kingdom and New York, NY, USA, 2013.

Kodera, K.: Influence of volcanic eruptions on the troposphere through stratospheric dynamical processes in the northern hemisphere winter, J. Geophys. Res., 99, 1273-1282, https://doi.org/10.1029/93JD02731, 1994.

Kodera, K.: Solar cycle modulation of the North Atlantic Oscillation: Implication in the spatial structure of the NAO, Geophys. Res. Lett., 29, 59-1-59-4, https://doi.org/10.1029/2001GL014557, 2002.

Kodera, K. and Kuroda, Y.: A possible mechanism of solar modulation of the spatial structure of the North Atlantic Oscillation, J. Geophys. Res., 110, D02111, https://doi.org/10.1029/2004JD005258, 2005.

Kravitz, B., Robock, A., Boucher, O., Schmidt, H., Taylor, K. E., Stenchikov, G. and Schulz, M.: The geoengineering model intercomparison project (GeoMIP), Atmos. Sci. Lett., 12, 162-167, https://doi.org/10.1002/asl.316, 2011.

Kravitz, B., Caldeira, K., Boucher, O., Robock, A., Rasch, P. J., Alterskjær, K., Karam, D. B., Cole, J. N., Curry, C. L., Haywood, J. M. and Irvine, P. J.: Climate model response from the Geoengineering Model Intercomparison Project (GeoMIP), J. Geophys. Res., 118, 8320-8332, https://doi.org/10.1002/jgrd.50646, 2013.

Kravitz, B., MacMartin, D. G., Robock, A., Rasch, P. J., Ricke, K. L., Cole, J. N. S., Curry, C. L., Irvine, P. J., Ji, D., Keith, D. W., Kristjánsson, J. E., Moore, J. C., Muri, H., Singh, B., Tilmes, S., Watanabe, S., Yang, S., and Yoon, J.-H.: A multi-model assessment of regional climate disparities caused by solar geoengineering, Environ. Res. Lett., 9, 074013, https://doi.org/10.1088/1748326/9/7/074013, 2014.

Kravitz, B., Robock, A., Tilmes, S., Boucher, O., English, J. M., Irvine, P. J., Jones, A., Lawrence, M. G., MacCracken, M., Muri, H., Moore, J. C., Niemeier, U., Phipps, S. J., Sillmann, J., Storelvmo, T., Wang, H., and Watanabe, S.: The Geoengineering Model Intercomparison Project Phase 6 (GeoMIP6): simulation design and preliminary results, Geosci. Model Dev., 8, 33793392, https://doi.org/10.5194/gmd-8-3379-2015, 2015.
Kravitz, B., MacMartin, D. G., Visioni, D., Boucher, O., Cole, J. N. S., Haywood, J., Jones, A., Lurton, T., Nabat, P., Niemeier, U., Robock, A., Séférian, R., and Tilmes, S.: Comparing different generations of idealized solar geoengineering simulations in the Geoengineering Model Intercomparison Project (GeoMIP), Atmos. Chem. Phys. Discuss. [preprint], https://doi.org/10.5194/acp-2020-732, in review, 2020.

Latham, J.: Control of global warming? Nature, 347, 339-340, https://doi.org/10.1038/347339b0, 1990.

López-Moreno, J. I. and Vicente-Serrano, S. M.: Positive and negative phases of the wintertime North Atlantic Oscillation and drought occurrence over Europe: a multitemporal-scale approach, J. Climate, 21, 1220-1243, https://doi.org/10.1175/2007JCLI1739.1, 2008.

Lorenz, D. J. and Hartmann, D. L.: Eddy-zonal flow feedback in the Northern Hemisphere winter, J. Climate, 16, 1212-1227, https://doi.org/10.1175/15200442(2003)16<1212:EFFITN>2.0.CO;2, 2003.

MacMartin, D. G., Keith, D. W., Kravitz, B., and Caldeira, K.: Management of trade-offs in geoengineering through optimal choice of non-uniform radiative forcing, Nat. Clim. Change, 3, 365-368, https://doi.org/10.1038/NCLIMATE1722, 2013.

Malavelle, F., Haywood, J. M., Jones, A., Gettelman, A., Clarisse, L., Bauduin, S., Allan, R. P., Karset, I. H., H., Kristjánsson, J. E., Oreopoulos, L., Cho, N., Lee, D., Bellouin N., Boucher, O., Grosvenor, D. P., Carslaw, K. S., Dhomse, S., Mann, G. W., Schmidt, A., Coe, H., Hartley, M. E., Dalvi, M., Hill, A. A., Johnson, B. T., Johnson, C. E., Knight J. R., O’Connor, F. M., Partridge, D. G., Stier, P., Myhre, G., Platnick, S., Stephens, G. L., Takahashi, H., and Thordarson, T.: Strong constraints on aerosol-cloud interactions from volcanic eruptions, Nature, 546, 485-491, https://doi.org/10.1038/nature22974, 2017.

Mann, G. W., Carslaw, K. S., Spracklen, D. V., Ridley, D. A., Manktelow, P. T., Chipperfield, M. P., Pickering, S. J., and Johnson, C. E.: Description and evaluation of GLOMAP-mode: a modal global aerosol microphysics model for the UKCA composition-climate model, Geosci. Model Dev., 3, 519-551, https://doi.org/10.5194/gmd-3-519-2010, 2010.

Matthes, K., Kuroda, Y., Kodera, K., and Langematz, U.: Transfer of the solar signal from the stratosphere to the troposphere: Northern winter, J. Geophys. Res., 111, D06108, https://doi.org/10.1029/2005JD006283, 2006.

Mills, M. J., Schmidt, A., Easter, R., Solomon, S., Kinnison, D. E., Ghan, S. J., Neely III, R. R., Marsh, D. R., Conley, A., Bardeen, C. G. and Gettelman, A.: Global volcanic aerosol properties derived from emissions, 1990-2014, using CESM1 (WACCM), J. Geophys. Res., 121, 2332-2348, https://doi.org/10.1002/2015JD024290, 2016.

Mills, M. J., Richter, J. H., Tilmes, S., Kravitz, B., MacMartin, D. G., Glanville, A. A., Tribbia, J. J., Lamarque, J.-F., Vitt, F., Schmidt, A., and Gettelman, A.: Radiative and chemical response to interactive stratospheric sulfate aerosols in fully coupled CESM1 (WACCM), J. Geophys. Res., 122, 13061-13078, https://doi.org/10.1002/2017JD027006, 2017.

Morgenstern, O., Braesicke, P., O’Connor, F. M., Bushell, A. C., Johnson, C. E., Osprey, S. M., and Pyle, J. A.: Evaluation of the new UKCA climate-composition model Part 1: The stratosphere, Geosci. Model Dev., 2, 43-57, https://doi.org/10.5194/gmd-2-43-2009, 2009. 
Mulcahy, J. P., Jones, C., Sellar, A., Johnson, B., Boutle, I. A., Jones, A., Andrews, T., Rumbold, S. T., Mollard, J., Bellouin, N., Johnson, C. E., Williams, K. D., Grosvenor, D. P., and McCoy, D. T.: Improved Aerosol Processes and Effective Radiative Forcing in HadGEM3 and UKESM1, J. Adv. Model. Earth Sy., 10, 2786-2805, https://doi.org/10.1029/2018MS001464, 2018.

Muntjewerf, L., Petrini, M., Vizcaino, M., Ernani da Silva, C., Sellevold, R., Scherrenberg, M.D., Thayer-Calder, K., Bradley, S. L., Lenaerts, J. T., Lipscomb, W. H. and Lofverstrom, M.: Greenland Ice Sheet Contribution to 21st Century Sea Level Rise as Simulated by the Coupled CESM2.1-CISM2.1, Geophys. Res. Lett., 47, e2019GL086836, https://doi.org/10.1029/2019GL086836, 2020.

Myhre, G., Shindell, D., Bréon, F.-M., Collins, W., Fuglestvedt, J., Huang, J., Koch, D., Lamarque, J.-F., Lee, D., Mendoza, B., Nakajima, T., Robock, A., Stephens, G., Takemura, T., and Zhang, H.: Anthropogenic and Natural Radiative Forcing, in: Climate Change 2013: The Physical Science Basis. Contribution of Working Group I to the Fifth Assessment Report of the Intergovernmental Panel on Climate Change, edited by: Stocker, T. F., Qin, D., Plattner, G.-K., Tignor, M., Allen, S. K., Boschung, J., Nauels, A., Xia, Y., Bex, V., and Midgley, P. M., Cambridge University Press, Cambridge, United Kingdom and New York, USA, 2013.

Niemeier, U., Schmidt, H., Alterskjær, K., and Kristjánsson, J. E.: Solar irradiance reduction via climate engineering: Impact of different techniques on the energy balance and the hydrological cycle, J. Geophys. Res., 118, 11905-11917, https://doi.org/10.1002/2013JD020445, 2013.

Niemeier, U. and Timmreck, C.: What is the limit of climate engineering by stratospheric injection of $\mathrm{SO}_{2}$ ?, Atmos. Chem. Phys., 15, 9129-9141, https://doi.org/10.5194/acp-159129-2015, 2015.

O’Neill, B. C., Tebaldi, C., van Vuuren, D. P., Eyring, V., Friedlingstein, P., Hurtt, G., Knutti, R., Kriegler, E., Lamarque, J.-F., Lowe, J., Meehl, G. A., Moss, R., Riahi, K., and Sanderson, B. M.: The Scenario Model Intercomparison Project (ScenarioMIP) for CMIP6, Geosci. Model Dev., 9, 3461-3482, https://doi.org/10.5194/gmd-9-3461-2016, 2016.

Pitari, G., Aquila, V., Kravitz, B., Robock, A., Watanabe, S., Cionni, I., Luca, N. D., Genova, G. D., Mancini, E., and Tilmes, S.: Stratospheric ozone response to sulfate geoengineering: Results from the Geoengineering Model Intercomparison Project (GeoMIP), J. Geophys. Res., 119, 2629-2653, https://doi.org/10.1002/2013JD020566, 2014.

Polvani, L. M., Banerjee, A., and Schmidt, A.: Northern Hemisphere continental winter warming following the $1991 \mathrm{Mt}$. Pinatubo eruption: reconciling models and observations, Atmos. Chem. Phys., 19, 6351-6366, https://doi.org/10.5194/acp19-6351-2019, 2019.

Rasch, P. J., Tilmes, S., Turco, R. P., Robock, A., Oman, L., Chen, C.-C., Stenchikov, G. L., and Garcia, R. R.: An overview of geoengineering of climate using stratospheric sulfate aerosols, Phil. T. Roy. Soc. A., 366, 4007-4037, https://doi.org/10.1098/rsta.2008.0131, 2008.

Riahi, K., Rao, S., Krey, V., Cho, C., Chirkov, V., Fischer, G., Kindermann, G., Nakicenovic, N., and Rafaj, P.: RCP 8.5 - A scenario of comparatively high greenhouse gas emissions, Clim.
Change, 109, 33-57, https://doi.org/10.1007/s10584-011-0149y, 2011.

Ridley, J. K., Blockley, E. W., Keen, A. B., Rae, J. G. L., West, A. E., and Schroeder, D.: The sea ice model component of HadGEM3-GC3.1, Geosci. Model Dev., 11, 713-723, https://doi.org/10.5194/gmd-11-713-2018, 2018.

Robock, A.: Volcanic eruptions and climate, Rev. Geophys., 38, 191-219, https://doi.org/10.1029/1998RG000054, 2000.

Robock, A.: Benefits and risks of stratospheric solar radiation management for climate intervention (geoengineering), Bridge, 50, 59-67, 2020.

Robock, A. and Mao, J.: Winter warming from large volcanic eruptions, Geophys. Res. Lett., 19, 2405-2408, https://doi.org/10.1029/92GL02627, 1992.

Robock, A., MacMartin, D. G., Duren, R., and Christensen, M. W.: Studying geoengineering with natural and anthropogenic analogs, Climatic Change, 121, 445-458, https://doi.org/10.1007/s10584-013-0777-5, 2013.

Rodwell, M. J., Rowell, D. P., and Folland, C. K.: Oceanic forcing of the wintertime North Atlantic Oscillation and European climate, Nature, 398, 320-323, https://doi.org/10.1038/18648, 1999.

Royal Society: Geoengineering the climate: Science, governance and uncertainty, RS Policy Document 10/09 RS1636, The Royal Society, London, UK, available at: https://eprints.soton.ac.uk/ 156647/1/Geoengineering_the_climate.pdf (last access: 22 January 2021), 2009.

Santer, B. D., Bonfils, C., Painter, J. F., Zelinka, M. D., Mears, C., Solomon, S., Schmidt, G. A., Fyfe, J. C., Cole, J. N., Nazarenko, L., and Taylor, K. E.: Volcanic contribution to decadal changes in tropospheric temperature, Nat. Geosci., 7, 185-189, https://doi.org/10.1038/ngeo2098, 2014.

Scaife, A. A., Folland, C. K., Alexander, L. V., Moberg, A., and Knight, J. R.: European climate extremes and the North Atlantic Oscillation, J. Climate, 21, 72-83, https://doi.org/10.1175/2007JCLI1631.1, 2008.

Scaife, A. A., Ineson, S., Knight, J. R., Gray, L., Kodera, K., Smith, D. M.: A mechanism for lagged North Atlantic climate response to solar variability, Geophys. Res. Lett., 40, 434-439, https://doi.org/10.1002/grl.50099, 2013.

Sellar, A., Jones, C. G., Mulcahy, J. P., Tang, Y., Yool, A., Wiltshire, A., O’Connor, F. M., Stringer, M., Hill, R., Palmieri, J., Woodward, S., de Mora, L., Kuhlbrodt, T., Rumbold, S., Kelley, D. I., Ellis, R., Johnson, C. E., Walton, J., Abraham, N. L., Andrews, M. B., Andrews, T., Archibald, A. T., Berthou, S., Burke, E., Blockley, E., Carslaw, K., Dalvi, M., Edwards, J., Folberth, G. A., Gedney, N., Griffiths, P. T., Harper, A. B., Hendry, M. A., Hewitt, A. J., Johnson, B., Jones, A., Jones, C. D., Keeble, J., Liddicoat, S., Morgenstern, O., Parker, R. J., Predoi, V., Robertson, E., Siahaan, A., Smith, R. S., Swaminathan, R., Woodhouse, M., Zeng, G., and Zerroukat, M.: UKESM1: Description and evaluation of the UK Earth System Model, J. Adv. Model. Earth Sy. 11, 4513-4558, https://doi.org/10.1029/2019MS001739, 2019.

Shindell, D. T., Schmidt, G. A., Miller, R. L., and Rind, D.: Northern Hemisphere winter climate response to greenhouse gas, ozone, solar, and volcanic forcing, J. Geophys. Res., 106, 7193 7210, https://doi.org/10.1029/2000JD900547, 2001.

Shindell, D. T., Schmidt, G. A., Mann, M. E., and Faluvegi, G.: Dynamic winter climate response to large tropical vol- 
canic eruptions since 1600, J. Geophys. Res., 109, D05104, https://doi.org/10.1029/2003JD004151, 2004.

Simpson, I. R., Tilmes, S., Richter, J. H., Kravitz, B., MacMartin, D. G., Mills, M. J., Fasullo, J. T., and Pendergrass, A. G.: The regional hydroclimate response to stratospheric sulfate geoengineering and the role of stratospheric heating, J. Geophys. Res., 124, 12587-12616, https://doi.org/10.1029/2019JD031093, 2019.

Smith, D. M., Scaife, A. A., Eade, R., and Knight, J. R.: Seasonal to decadal prediction of the winter North Atlantic Oscillation: emerging capability and future prospects, Q. J. Roy. Meteor. Soc., 142, 611-617, https://doi.org/10.1002/qj.2479, 2016.

Solomon, S.: Stratospheric ozone depletion: A review of concepts and history, Rev. Geophys., 37, 275-316, https://doi.org/10.1029/1999RG900008, 1999.

Stenchikov, G. L., Kirchner, I., Robock, A., Graf, H.-F., Antuña, J. C., Grainger, R. G., Lambert, A., and Thomason, L.: Radiative forcing from the 1991 Mount Pinatubo volcanic eruption, J. Geophys. Res., 103, 13837-13857, 1998.

Stenchikov, G., Robock, A., Ramaswamy, V., Schwarzkopf, M. D., Hamilton, K., and Ramachandran, S.: Arctic Oscillation response to the 1991 Mount Pinatubo eruption: Effects of volcanic aerosols and ozone depletion, J. Geophys. Res., 107, 4803, https://doi.org/10.1029/2002JD002090, 2002.

Storkey, D., Blaker, A. T., Mathiot, P., Megann, A., Aksenov, Y., Blockley, E. W., Calvert, D., Graham, T., Hewitt, H. T., Hyder, P., Kuhlbrodt, T., Rae, J. G. L., and Sinha, B.: UK Global Ocean GO6 and GO7: a traceable hierarchy of model resolutions, Geosci. Model Dev., 11, 3187-3213, https://doi.org/10.5194/gmd-11-3187-2018, 2018.

Thomson, A. M., Calvin, K. V., Smith, S. J., Kyle, G. P., Volke, A., Patel, P., Delgado-Arias, S., Bond-Lamberty, B., Wise, M. A., Clarke, L. E., and Edmonds, J. A.: RCP4.5: A pathway for stabilization of radiative forcing by 2100 , Climatic Change, 109 , 77-94, https://doi.org/10.1007/s10584-011-0151-4, 2011.

Tilmes, S., Garcia, R. R., Kinnison, D. E., Gettelman, A., and Rasch, P. J.: Impact of geoengineered aerosols on the troposphere and stratosphere, J. Geophys. Res., 114, D12305, https://doi.org/10.1029/2008JD011420, 2009.
Tilmes, S., Richter, J. H., Kravitz, B., MacMartin, D. G., Mills, M. J., Simpson, I. R., Glanville, A. S., Fasullo, J. T., Phillips, A. S., Lamarque, J.-F., Tribbia, J., Edwards, J., Mickelson, S., and Ghosh, S.: CESM1(WACCM) Stratospheric Aerosol Geoengineering Large Ensemble Project, B. Am. Meteor. Soc., 99, 2361-2371, https://doi.org/10.1175/BAMS-D-17-0267.1, 2018.

Tilmes, S., MacMartin, D. G., Lenaerts, J. T. M., van Kampenhout, L., Muntjewerf, L., Xia, L., Harrison, C. S., Krumhardt, K. M., Mills, M. J., Kravitz, B., and Robock, A.: Reaching 1.5 and $2.0^{\circ} \mathrm{C}$ global surface temperature targets using stratospheric aerosol geoengineering, Earth Syst. Dynam., 11, 579601, https://doi.org/10.5194/esd-11-579-2020, 2020.

Walters, D., Baran, A. J., Boutle, I., Brooks, M., Earnshaw, P., Edwards, J., Furtado, K., Hill, P., Lock, A., Manners, J., Morcrette, C., Mulcahy, J., Sanchez, C., Smith, C., Stratton, R., Tennant, W., Tomassini, L., Van Weverberg, K., Vosper, S., Willett, M., Browse, J., Bushell, A., Carslaw, K., Dalvi, M., Essery, R., Gedney, N., Hardiman, S., Johnson, B., Johnson, C., Jones, A., Jones, C., Mann, G., Milton, S., Rumbold, H., Sellar, A., Ujiie, M., Whitall, M., Williams, K., and Zerroukat, M.: The Met Office Unified Model Global Atmosphere 7.0/7.1 and JULES Global Land 7.0 configurations, Geosci. Model Dev., 12, 1909-1963, https://doi.org/10.5194/gmd-12-1909-2019, 2019.

Yool, A., Popova, E. E., and Anderson, T. R.: MEDUSA-2.0: an intermediate complexity biogeochemical model of the marine carbon cycle for climate change and ocean acidification studies, Geosci. Model Dev., 6, 1767-1811, https://doi.org/10.5194/gmd6-1767-2013, 2013.

Zanardo, S., Nicotina, L., Hilberts, A. G., and Jewson, S. P.: Modulation of economic losses from European floods by the North Atlantic Oscillation, Geophys. Res. Lett., 46, 2563-2572, https://doi.org/10.1029/2019GL081956, 2019. 